University of Rhode Island

DigitalCommons@URI

Open Access Master's Theses

2021

\title{
TEMPERATURE-COMPENSATED STRAIN GAUGES USING METALSEMICONDUCTOR NANOCOMPOSITES
}

Matthew T. Ricci

University of Rhode Island, mricci593@gmail.com

Follow this and additional works at: https://digitalcommons.uri.edu/theses

\section{Recommended Citation}

Ricci, Matthew T., "TEMPERATURE-COMPENSATED STRAIN GAUGES USING METALSEMICONDUCTOR NANOCOMPOSITES" (2021). Open Access Master's Theses. Paper 1945.

https://digitalcommons.uri.edu/theses/1945

This Thesis is brought to you for free and open access by DigitalCommons@URI. It has been accepted for inclusion in Open Access Master's Theses by an authorized administrator of DigitalCommons@URI. For more information, please contact digitalcommons-group@uri.edu. 
TEMPERATURE-COMPENSATED STRAIN GAUGES USING METALSEMICONDUCTOR NANOCOMPOSITES

BY

MATTHEW T. RICCI

A THESIS SUBMITTED IN PARTIAL FULFILLMENT OF THE REQUIREMENTS FOR THE DEGREE OF MASTER OF SCIENCE

IN

CHEMICAL ENGINEERING

UNIVERSITY OF RHODE ISLAND

2021 


\section{MASTER OF SCIENCE THESIS}

OF

MATTHEW T. RICCI

\section{APPROVED:}

Thesis Committee:

$\begin{array}{ll}\text { Major Professor } & \text { Otto J. Gregory } \\ & \text { Alan J. Davis } \\ & \text { Everett E. Crisman } \\ & \text { Tao Wei } \\ & \text { Brenton DeBoef } \\ \text { DEAN OF THE GRADUATE SCHOOL }\end{array}$

UNIVERSITY OF RHODE ISLAND

2021 


\begin{abstract}
The goal of this work is to develop a strain gage system which incorporates the aforementioned characteristics. To develop a sensor with embedded temperature compensation, a nanocomposite thin film sensing element was designed and fabricated. These nanocomposite films were prepared by mixing refractory metals such as tungsten, nickel or palladium, having a large, positive temperature coefficient of resistance (TCR) with a semiconductor such indium tin oxide (ITO) having a large negative TCR. The resultant was an optimal mixture of the two components alloys with a minimal TCR over an extended temperature range. The focus of this study was to investigate the plausibility of a self-temperature compensated nanocomposite alloy for use as the static strain elements in a thin film strain gage at elevated temperatures. Nanocomposite films were sputter deposited on a thin, flexible YSZ ceramic membrane substrates to facilitate easy attachment to sample surfaces with minimal interference from the sensor platform so that the measured strain is due to the compliance of the material to which the strain gage was attached. The purpose of the study was not to produce an optimized strain gage with near zero TCR and large gage factor, but rather provide an approach or roadmap to develop nanocomposites for static strain gage applications where low TCR's are required.
\end{abstract}




\section{ACKNOWLEDGMENTS}

I sincerely thank Dr. Otto Gregory for his guidance, support, mentorship and patience during this work. His enthusiasm in this field made a strong impact on the direction for my academic and professional career.

I would also like to thank Mike Platek for helping keep the laboratory in functional shape and Vince Wnuk for funding part of this work and for helpful discussions. I'd thank my close friend and colleague Kevin Rivera for great discussions, research-related or not, and for his support throughout my undergraduate and graduate career.

Additional thanks to my friends and colleagues from both URI and MIT Lincoln Laboratory, without their constant support and motivation, I would not have the privilege to share this work with you. To my mother, Lori, father, Tom, brother Thomas and my grandparents for their support and patience while putting up with my many bouts of frustration and stress, thank you.

This work would not have been possible without support and access to many facilities. Thank you Mike Platek and Dr. Irene Andreu for SEM and EDS access and support. From MIT Lincoln Laboratory, I would like to especially thank Dr. Paul Juodawlkis and Jason Plant, for without their support I would been unable to accomplish much of my thesis-related efforts at Lincoln. I would lastly like to thank Scott Eastwood for allowing access to the Compound Semiconductor Laboratory to perform a part of this research and Daniel Calawa for assistance with XRD interpretation and Paul Miller for useful metrology discussions. 


\section{TABLE OF CONTENTS}

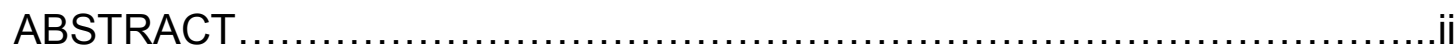

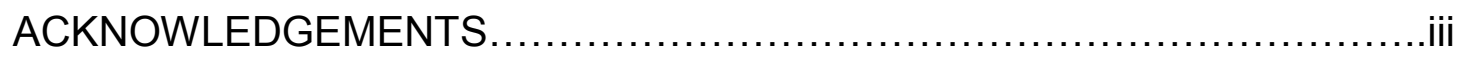

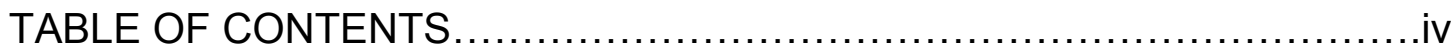

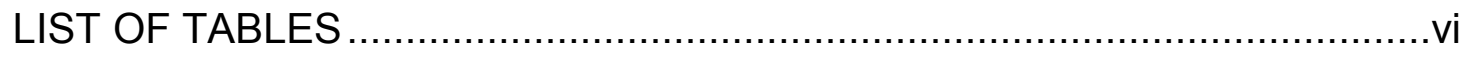

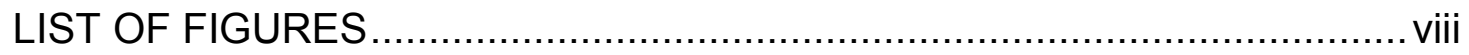

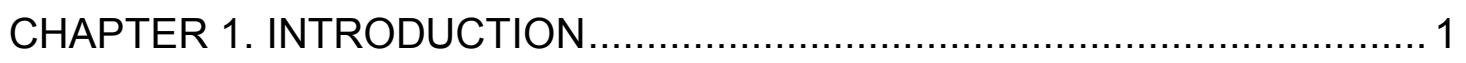

CHAPTER 2. LITERATURE REVIEW $\ldots \ldots \ldots \ldots \ldots \ldots \ldots \ldots \ldots \ldots \ldots \ldots \ldots \ldots \ldots \ldots \ldots 4$

2.1 Srain Gauge Fundamentals ............................................................................. 4

2.2 Thin Flm Strain Gauges. .....................................................22

2.3 Temperature Compensated Srain Gauges. ..................................27

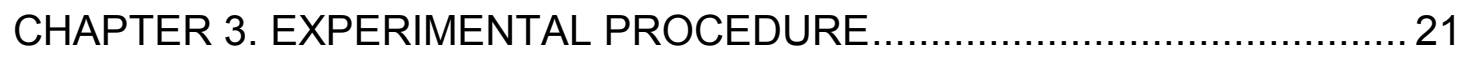

3.1 Indium Tin Oxide Strain Gauges on Thin Alumna Substrates....................................21

3.2 Tungsten:ITOand Nickel:ITOStrain Gauges on YSZSubstrates. .....................33

3.3 Pd:ITODeposition via Planar Co-Sputtering...................................37

3.4 Composite Strain Eement Deposition via Confocal Co-Sputtering.....................37

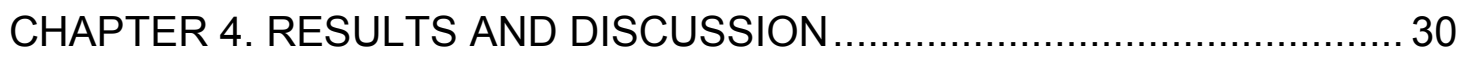

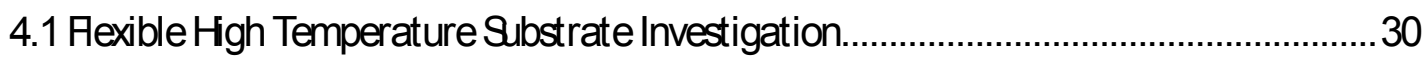

4.2 Tungsten:ITOand Nickel:ITOStrain Gauges on YSZSubstrates ......................42

4.3 Pd:ITOStrain Gauges via Planar Co-Sputtering .................................46

4.4 Composite Strain Eement Deposition via Confocal Co-Sputtering ....................48

CHAPTER 5. CONCLUSION AND FUTURE WORK .......................... 44

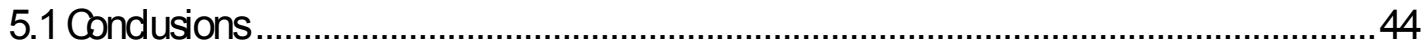




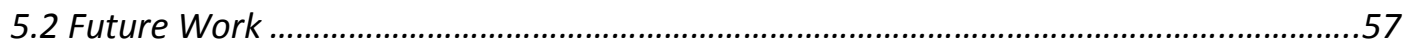

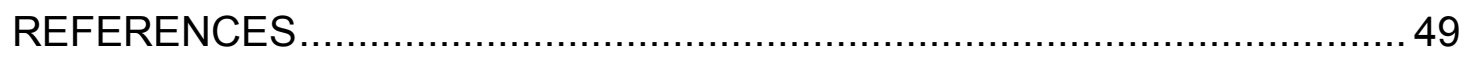

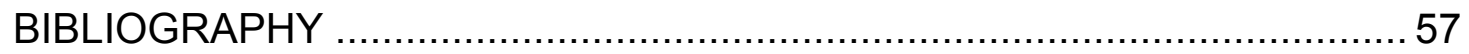




\section{LIST OF TABLES}

Table 1. Literature survey of temperature compensated thin film strain gauges.

Table 2. Deposition conditions and parameters for Ni:ITO confocally co-

sputtered composites at $2 \mathrm{mTorr}$.

Table 3. TCR and gauge factor of Ni:ITO composites fabricated via target processing. Deposition occurred for two hours at 400W RF power at 9mTorr in an argon ambient.

Table 4. Composition analysis of Ni:ITO confocal co-sputtered thin films on YSZ substrates collected using EDS with 20kV accelerating voltage.

Table 5. Composition analysis of Ni:ITO confocally co-sputtered thin film on $<100>$ silicon substrates with 500nm SiO2 collected using EDS with 20kV accelerating voltage. 48 Table 6. Summary of thermoresistive properties of planar sputtered Pd:ITO composites at a combined power of $400 \mathrm{~W}$ at a chamber pressure of $9 \mathrm{mT}$ Torr in Ar. 
Table 7. Summary of measured TCR to $350 \mathrm{C}$ and room temperature compressive gauge factor for 0.5 um thickness confocally co-sputtered Ni:ITO films deposited at $2 \mathrm{mTorr}$ in Ar. 49 Table 8. Carrier mobility and sheet carrier concentration for Ni:ITO confocally sputtered films at 1 tesla. 52 


\section{LIST OF FIGURES}

Figure 1. Influence of compressive and tensile strain on a typical metal foil

strain gauge.

Figure 2. Schematic illustration of a planar (top) and confocal (b) configured co-sputtering system (a).

20

Figure 3. Film characteristics as a function of deposition parameters

Figure 4. Thornton film growth zones

Figure 5. Pattern transfer process using photolithographic liftoff 22

Figure 6. Cartoon of the Hall Effect (a), a typical van der Pauw geometry used for evaluation of hall voltage. 24

Figure 7. Powder processing workflow (top), W:ITO target after sintering at $550 \mathrm{C}$ in N2 (bottom, upper), Ni:ITO ready for loading into sputter chamber (bottom, lower) and source powder loaded into die for hydraulic pressing for densification (bottom right).

Figure 8. MHI Microheater test setup for TCR characterization to $400 \mathrm{C}$ (top) Tube furnace setup for measurement of strain at elevated temperatures (bottom)

Figure 9. Jig used for room temperature evaluation of compressive gauge factor. Ni:ITO composites are deposited on YSZ substrates and are bonded to a Kapton carrier for handling and electrical connections. 37 Figure 10. ITO strain gage fabricated on thin alumina substrate. This gage is bonded to a CMC test article. 
Figure 11. ITO strain gage array processed on HVOF alumina/aluminum mandrel (top left), release layer failure during ITO liftoff (top right), severe cracking oh HVOF alumina due to release layer swelling (bottom).

Figure 12. ITO strain gages fabricated on flexible 40um thick $3 \mathrm{~mol} \% \mathrm{YSZ}$ substrates. 42

Figure 13. Non-linear strain response of a $95 \mathrm{wt} . \% \mathrm{~W}$ :ITO composite 44

Figure 14. Casino simulations for electron interaction energy decay @ 20KV and $10 \mathrm{~nm}$ beam diameter for ITO (top) and nickel (bottom). 45

Figure 15. Palladium content as determined by EDS for various Pd:ITO composite samples 46

Figure 16. Plot of TCR evaluated at $200 \mathrm{C}$ of various Pd:ITO composites..... 47

Figure 17. Pd:ITO strain gauge resistance as a function of increasing palladium content. 48

Figure 18. Pd:ITO SEM image. There is decreasing palladium content and a notable film morphology difference across the shown resistor stripe (top), schematic image of micromasking caused by oblique deposition angles and photoresist thickness (bottom).

Figure 19. Measured film stress of various Ni:ITO confocally sputtered composite films with a nominal thickness of 0.5 micron measured before annealing 50

Figure 20. TCR (a), linearity of gauge factor (b) and room temperature compressive gage factor of confocally sputtered Ni:ITO composites 51 Figure 21. Cross sectional SEM of confocally co-sputtered Ni:ITO composites 
on silicon substrates

Figure 22. Secondary electron SEM images collected of Ni:ITO confocally cosputtered composites on YSZ substrates.

Figure 23. Sheet resistance, carrier concentration and hall mobility of various

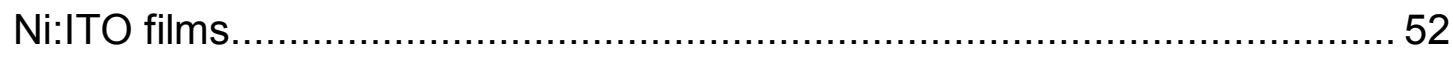




\section{INTRODUCTION}

Measurement of mechanical strain at elevated temperatures is fundamentally important to gas turbine manufacturers as higher operating temperatures are pushed to the material limit to increase engine efficiency and fuel economy. Towards this end, iron-based superalloys such as Incoloy ${ }^{\circledR} 909$ or Thermospan ${ }^{\circledR}$, and nickel-based superalloys such as Incoloy ${ }^{\circledR} 783$ are being displaced in the engine hot section by ceramic matrix composites (CMCs) and refractory metal intermetallics, such as niobium silicide for a number of applications in the jet engine hot section [13]. To further complicate matters, oftentimes to provide erosion resistance, and thermal, manufactures use refractory (ceramic) coatings known as thermal barrier coatings (TBCs). Thermal sprayed or plasma sprayed oxide-based coatings such as stabilized zirconia (YSZ), mullite or alumina [4] and more recently metal-glass composites known as micro/nanocermets are being used to provide additional protection for operation in harsh environments [5].

Given this material shift, careful thought must be given to the instrumentation of critical parts in gas turbine engines. For higher temperature applications, the shift to ceramic matrix composites for their superior toughness, temperature stability [6] and light weight [7] means sacrificing weldability. As materials move from metallics to ceramics, welding to the component is no longer an option. Hence, for high temperature applications, instrumentation including strain gages and 
thermocouples must be applied using refractory cements instead of conventional welding techniques. Conventional instrumentation for high temperature strain measurement is typically done using wire-wound strain gages. These sensors are resistive strain devices whose strain can be correlated with a measurable change in resistance. These wire-based sensors are stable to temperatures to $980 \mathrm{C}$ using a Hoskins ${ }^{\mathrm{TM}} 875$ alloy [8], however, they are typically on the order of 200-400um in thickness [9] so they protrude into the boundary layer thickness and interrupt airflow. Another downside to wire strain gages is their rather poor sensitivity to strain. Thin film strain gages offer several advantages over wire-based strain gages. A profile on the order of tens of micrometers, means that thin film instrumentation is minimally intrusive but can also tolerate high temperatures (often exceeding 1000C) and exhibit high sensitivities [10], However, fabrication of these sensors directly onto engine components can prove difficult if the parts are large or have complex geometriesnecessitating large, complex, and expensive vacuum deposition equipment. For lower temperature strain measurement applications $(<250 \mathrm{C})$, metal foil strain gages are the benchmark for both static and dynamic strain measurement. These gages consist of an etched metal serpentine typically made of Constantan, a copper-nickel alloy, or Nichrome, or a nickel-chrome alloy sandwiched between two polyimide sheets [11]. These alloys have a low sensitivity to temperature effects, a characteristic called the thermal coefficient of resistivity (TCR). The goal of 
this research effort is to achieve suitably low TCR strain gauges which are capable of operation at temperatures higher than that of conventional metal foil strain gauges. 


\section{LITERATURE REVIEW}

\subsection{Strain Gauge Fundamentals}

The first documented experiments leading to the invention of today's strain gages were performed in 1856 by Lord Kelvin, with the observation of resistance changes of nickel and iron wires when exposed to magnetically induced strain [12]. Charles Kearns, prompted by frequent failure of aircraft propellers during World War 1 , who finally began utilizing this property. Kearns cemented a sulfur-carbon composite, also known as Aquadag, resistance strain gauges to aircraft propellers in an attempt to measure mechanical strain to diagnose propeller failure [13]. In these early sensors, electrical resistance correlated linearly with strain, however, other factors such as resistance (drift) variability over time, humidity, and temperature obfuscated the output of the sensor [14]. MIT's Arthur Ruge and Caltech's Edward Simmons began mastering application of these devices with their breakthrough SR-1 wirewound strain gage. Their 1941 US Patent entitled 'Strain Gauge' describes strain gages consisting of a nichrome or Advance (Copper-nickel alloy) wire serpentine bonded to a paper backing insulated using felt to help reduce environmental noise [13]. The two easily commercialized the wire-based strain gages to meet the demands of the growing aircraft industry during the Second World War.

Today, strain gage sensors are used in a number of applications including infrastructure monitoring [15], detection of seismological activity [16], and even in implant protheses for medical applications [17]. Strain may either 
be a positive quantity (tensile stress) or a negative quantity (compressive stress). Two 'classes' of strain defined by the timescale of deformation. Static strain occurs on the seconds timescale, measurements typically occur on the component level for validation of FEA (finite element analysis) models or to determine safety factors by testing parts until failure. Dynamic strain cycles occur at tens to hundreds of thousands of hertz, and thus are useful for system level analysis, and fatigue analysis- a large failure mode for metals which work harden and embrittle over repeated strain cycles.

The typical resistance strain gauge design differs little to early iterations of the sensor, typically consisting of a wire or metal foil in a meandering pattern. Resistance changes for metal strain gauges are primarily geometry dependent. Deformation as either elongation or compression changes the resistance of the strain element and is depicted in figure 1. By supplying an electrical current and simultaneously measuring the voltage drop across the device, changes in resistance can be observed. The baseline, or resting, resistance is the resistance at which the gauge measures under ambient conditions under no applied load. The orientation of the strain gage 'legs' is important in maximizing strain sensitivity of the sensor only in a particular direction. It is useful to express the strain gage's sensitivity in terms of the magnitude of resistance change- this quantity is known as the gage factor ( $G$ or GF) and is generally given by the following equation (1): 
where $R$ is electrical resistance and $\varepsilon$ is strain. The change in resistance of metals as a function of strain is primarily due to dimensional changes in the device and is represented in the first two terms of equation (2).

Semiconductors, however, often exhibit a material property called piezoresistivity which also greatly contributes to resistance change as a function of temperature. Piezoresistive properties of semiconductors arise from changes in band structure due to changes in inter-atomic spacing and piezoresistance is accounted for in the last term of equation two. Gauge factor can then be defined as the sum of resistance changes as a function of dimensional change as well as the contribution by piezoresistance: 
piezoresistive materials make them highly immune to electrical noise and ideal for measurements of small quantities of strain (>500 microstrain).

Exposure of a device to elevated temperatures over a period of time causes a change in its baseline resistance. A quantity that describes this is called the drift rate, or DR and is defined as 
measurements, these materials should be carefully chosen to minimize TCE differences and thus thermally induced strain. This quantity is called the thermal coefficient of gage factor, TCGF, is given by eq. 6 below: 
direction. Electrical connections to these devices are typically made using soldered wires for lower temperature connections. Higher temperature applications require careful consideration of the method and materials used during leadwire attachment. These types of strain gages are particularly popular due to low costs, simple circuitry, and linearity. Foil gauges are perhaps the most widely used style of strain gage. These are typically fabricated by lamination of a metal foil (Nichrome or Constantin) on a polymer sheet such as polyimide or a phenolic epoxy. A chemical etching process, similar to that used in printed circuit board manufacturing, defines the gages shape, bonding pads are electroplated and tinned for solder wettability, and the serpentine is laminated with another sheet of polymer for enhanced protection against abrasion, corrosion and for electrical isolation. Bonding of a typical foil gauge to the test article typically involves the use of cyanoacrylate glue while lead attachment is accomplished using soldered electrical connections. This type of strain gage, like most metallic strain gages, shows great linearity, stability over time and is well suited towards both static and dynamic strain measurement. While versatile, they do not allow for operation in excess of $250 \mathrm{C}$ due to decomposition of the polymer substrate [20] and a large CTE mismatch between the metallic strain element and polymer substrate.

Wire strain gages are popular for high temperature measurements. These devices consist of a metal wire filament that acts as the strain sensing element. A number of wire alloys are used, with choice dependent on the 
application. Platinum tungsten wire, for instance, is usable to $1038 \mathrm{C}$ and exhibits a low, stable TCR [21]. Weldable wire wound strain gages can be encapsulated in flame sprayed ceramics for stability and bonded to metal coupons with necessary wire lead outs for data acquisition. For application to nonmetallic surfaces such as ceramics or composite materials, they may be directly cemented to the surface in a fiberglass carrier. Wire wound strain gages exhibit great stability to temperature drift and fatigue life depending on the wire alloy chosen, however their downside is their high cost relative to other methods, and relatively thick construction (>200um). This can prove limiting in applications where there is little physical clearance between two parts such as between stators and rotors in aircraft turbines, where the thickness of the strain gage is beyond the air boundary layer thickness, which can cause disturbances in airflow.

\subsection{Thin Film Strain Gauges}

Unlike their wire counterparts, thin film strain gauges have very low surface profiles and thus do not result in a change of aerodynamic, thermal and structural change of the blade. The low profile of thin film instrumentation allows for non-intrusive application of these sensors even in tight tolerance spaces, without compromising airflow within the device, since the height of the thin film gauges are well below the boundary layer thickness. Thin film strain gauges also have faster response times making them more suitable for high resolution measurements. 
Thin film elements are typically deposited using a physical vapor deposition technique called sputtering. This thin film deposition process takes place under vacuum typically from $0.1-200$ mTorr. Plasma is typically generated in one of two ways, in a diode or triode discharge configuration or a magnetron configuration. A diode/triode discharge configuration typically consists of two electrodes separated by vacuum and connected to a DC or RF high voltage power supply to apply potential and strike a plasma. A magnetron configuration introduces a magnetic field parallel to the source material, or target, surface to increase plasma confinement, resulting in operation at lower pressures and voltages. In either case, ionized gas is directed towards this pure target of material to kinetically remove source atoms and deposit on a substrate into a dense film. As will be discussed later in this paper, sputter chamber geometry is also a considering when depositing material from two targets simultaneously. Figure 2 describes a planar co-sputtering arrangement and confocal cosputtering arrangement.

Deposited film characteristics such as stress, morphology and resistivity are highly influenced by deposition parameters chosen during the sputtering process. Important variables to note are the base pressure of the vacuum system, the chamber pressure during sputtering, sputtering power and power density, deposition temperature and substrate RF bias. Figure 3 shows the influence of these parameters on resulting film characteristics. Influences of these process parameters on film structure are generally characterized in 
'zones', which show film structure is strongly dependent on deposition pressure and the relative substrate temperature during film deposition. A common visualization for this relationship is depicted in the so-called Thornton growthzone model in figure 4.

Pattern generation for deposited thin films may be accomplished in a number of ways. A simple method of patterning involves depositing through a stencil called a shadow mask to block film deposition in select areas to define a pattern. For smaller and more complex features, a process called photolithography is used. This process is typically performed in two ways, etchback or liftoff. Either method usually involves application of a photoresist, a photosensitive polymer which either becomes developable in alkaline solutions when exposed to sufficient doses of UV light (positive photoresist) or becomes crosslinked and resistant to development in alkaline solutions (negative photoresist). For an etch back process, film is deposited over the entire substrate. Photoresist is applied, and UV light is selectively applied to certain areas of the coated substrate using a photomask. The pattern is then defined after developing the unwanted photoresist in an alkaline solution (typically aqueous solutions of potassium hydroxide or tetramethyl ammonium hydroxide). The deposited film is then etched away to define the pattern, which may either be done using a wet etch, or a dry etch which involves use of ionized etchant vapors. The photoresist is then removed to reveal the desired pattern. The liftoff process is slightly different and first involves application and patterning of the 
photoresist on the substrate as previously described. This is followed by deposition of the film of interest over the photoresist coated substrate. The underlying photoresist is then dissolved away, 'lifting-off' the film on top of it. Liftoff processes have the advantage of being able to deposit arbitrary materials and not have to consider etchant chemistry for removal. Some disadvantages of the liftoff method are typically worse attainable resolution during patterning, and the inability to deposit films at temperatures beyond the decomposition or reflow temperature of photoresists (typically $>120$ C). A schematic illustration depicts these three processes in figure 5.

Commercially used gages are made out of a number of materials including platinum, nichrome and palladium-chrome. Application of these sensors occurs directly on the test article, so no addition layers of adhesive or bonding material need be applied unless a dielectric is necessary for electrical isolation. This process begins with preparation of the test article surface to remove any contaminants such as debris or oils as well as mechanical polishing to remove any pinholes or cracks on the surface. A masking step provides the pattern of the strain gage, photolithography or shadowmasking are typical. After being masked, the part is loaded into a vacuum chamber where deposition of the strain active element and any contacts occurs typically via a physical vapor deposition process such as sputtering or vacuum evaporation. An approach circumventing the need for any high-resolution masking involves deposition of a dielectric oxide and a thin film resistive alloy. This is followed by a 
laser ablation process where excess material is vaporized to create the desired strain gage design. Thin film strain gages have very high resistance to creep, or fatigue, as there are no (or very thin) intermediate materials. Their downside, however, is that large and expensive vacuum deposition equipment is needed for part instrumentation, particularly a challenge for physically large components or parts with complex geometry.

$\operatorname{PdCr}(87: 13)$ thin film strain gauges developed by NASA were a leading candidate for static strain measurements at one time [22]. These gauges suffered from internal oxidation of $\mathrm{Cr}$ in the alloy at temperatures above $800 \mathrm{C}$. Typically efforts to expand the usable temperature range of thin film sensors focus on preventing or reducing oxidation through use of overcoats. To improve the strain gauge made by NASA, a protective coating of $\mathrm{Cr}$ layer that would be oxidized to form a single passivating oxide $\mathrm{Cr} 2 \mathrm{O} 3$.

Using these passive oxide overcoats, it should be considered that addition of thin film layers may cause oxide scale buckling due to increased compressive stresses leading to a non-passivating coating [23]. This work resulted in a strain package capable of reliable dynamic strain measurement at temperatures up to $1000 \mathrm{C}$ in air for 12,000 cycles of 1100 microstrain over a $100 \mathrm{~h}$ period. This sensor was reliable at high temperatures, but with a TCR of $\sim 600$ $\mathrm{ppm} / \mathrm{C}$, and a gage factor of 1.3 there was room for improvement. Semiconductors exhibit a large gage factors (GF $>100$ ), as do discontinuous metal films $(\mathrm{GF} \sim 30)$ however these materials are not well suited for operation at high temperatures [19] due to their high TCR. A very promising choice for 
strain measurement materials are heavily doped wide-bandgap metal oxide semiconductors. Changes in interatomic spacing during strain alters the bandgap of the material, changing the energy needed for excitation of an electron from the valence to the conduction band which results in a change in charge carrier concentration thus affecting resistivity of the material.

One method to gain insight into some of the conduction mechanisms in a material are making measurements using the hall-effect. This effect is observed when applying an electrical current perpendicular to a magnetic field to produce a voltage difference and is illustrated in figure 6 . The voltage produced can then be related to charge carrier concentration and carrier mobility in the sample under test using the equation (7) below, where $\rho$ is the electrical resistivity in $\Omega-\mathrm{cm}, \mathrm{q}$ is the electron charge in $\mathrm{C} / \mathrm{cm}^{2}, \mathrm{n}$ is the carrier concentration in $\mathrm{cm}^{-3}$ and $\mu$ is the carrier mobility in $\mathrm{cm}^{2} / \mathrm{V} s$. 
style of sensor offers large gage factors between 100 and 155, but also has large TCGF and TCRs between -18 and $-9 \%$ and 24 and $5 \%$ respectively which limits their practicality for elevated temperature measurements without complex circuitry or compensation techniques [19].

A material of particular interest in high temperature strain measurement is indium tin oxide (ITO). ITO is a transparent, thin, conductive metal oxide semiconductor often used in displays and polymer-based electronics. ITO is a degenerate n-type semiconductor and is a particularly good appealing candidate for active strain elements in thin film strain sensor applications at high temperature because of its large piezoresistive response and high temperature stability. ITO's high temperature stability is due to its extensive solid solution phase present over a large range of temperatures in oxygen ambient up to 1500C. In nitrogen ambient, however, dissociation may occur temperatures as low as $1200 \mathrm{C}$. Failure in the oxygen ambient at $1500 \mathrm{C}$ is due to its decomposition by sublimation [24].

Oxygen deficient ITO films (90 wt. \% In2O3 and 10 wt. \% SnO2 were the strain active element in these series of tests performed by Gregory et al [26]. Tests of these devices yielded repeatable TCRs in the thin films from $429 \mathrm{ppm} / \mathrm{C}$ at room temperature and as high as $-1560 \mathrm{ppm} / \mathrm{C}$ at $1100 \mathrm{C}$ in an air ambient. Additionally, a gage factor as large as -77.71 was observed at room temperature [25]. Such large gage factors were realized with this film due to band structure changes as a result of applied strain. Gage factor was also evaluated optically using of UV-Vis spectroscopy while being strained up 
to 700 microstrain. Examining these spectra placing the device in compression the optical bandgap increased while the opposite was true when the sample was placed under tension.

\subsection{Temperature Compensated Strain Gages}

Considering the large gage factor that can be achieved through use of a wide bandgap semiconductor as well as TCR values that are negative, the combination of a positive TCR metal could make a sensor with the desired characteristics. The result of this would be a strain gauge where TCR and gage factor may be tuned to reach desired thermoelectric characteristics by adjusting composition. A first attempt at TCR compensation was using an ITO strain element in series with a platinum resistor. The result of this experiment was a self-compensating ITO sensor with a TCR of near zero from 25-1200C. Similar to the uncompensated ITO gauge discussed earlier, this sensor was capable operation in temperatures to $1200-1450 \mathrm{C}$. The downside to this method of temperature compensation, however, is the resulting gage factor of only due to the extra resistance in the circuit contributed by the platinum resistor. The self-compensating sensor produced in this work showed a gage factor of -5.3 for a 6 micron thick gauge as compared to a gage factor as large as -77 for a gauge of similar thickness shown in [25].

Nanocomposites are multiphasic materials whose characteristic dimension is $<100 \mathrm{~nm}$. Broadly, this encompasses a number of types of materials: porous materials, colloids and copolymers. Aside from particles, the 
filler phase of nanocomposites can also be layered sheets, such as in nanoclay composites [27] or fibrous material such as electrospun fibers or carbon nanotubes [26,31]. In general, the combination of two or more materials at the nanoscale results in a material whose mechanical, optical, thermal electrical or catalytic properties are greatly enhanced, or that distinctly differ from the materials they are composed of. Rafiee et al. for example, investigated epoxy nanocomposites with SWCNTs, MWCNTs and graphene platelets and found enhancements for Young's modulus, tensile strength and fatigue resistance at low loading percentages [27]. Nanocermets, nanoscale mixtures of ceramics and metals, show markedly different optical materials and can be used to tune absorption and emissivities of the composite system for solar power generation $[29,30]$. For thermopower generation, nanocermet Pt-Al2O3 thin film thermopiles were developed to minimize thermal conductivity and maximize Seebeck coefficient and electrical conductivity to enhance energy conversion efficiency [30].

This process is dependent on nanoparticle size, spacing and volume percent. The percolation threshold is used to describe the loading percentage where contiguity of the metallic phase is observed- exceeding the percolation threshold, electron tunneling is reduced and typical electronic conduction is observed. Alamusi et al. demonstrated gage factors of 23 using a polyvinyldifluoride (PVDF) matrix- multiwalled carbon nanotube (MVNT) composite at $1 \%$ volume loading [32]. 
As previously mentioned, one can also mitigate some temperature effects solely by materials choice. Metals typically exhibit increasing resistance as a function of temperature, while semiconductors generally show the opposite effect. Using a simple mixture rule, one could engineer a composite material that shows little to zero change in resistance as a function of temperature. This is one focus of the current work. Metals typically will have a positive temperature coefficient of resistivity. As temperature increases, vibrational energy of lattice atoms also increases, increasing collision frequency and lowering electron mobility-raising resistance. N-type semiconductors, on the other hand, typically exhibit a negative temperature coefficient of resistance which can be explained by changes in electronic band structure. In metals, phonon vibrations can lead to resistance changes. Additionally, charge-carrier concentration increases with increasing temperature due to a shift in valence band energy, as a result lowering resistance. These two competing effects govern a semiconductors electrical properties as a function of temperature and are a factor in the nonlinearity of resistivity in semiconducting films.

Gregory et. al demonstrate use of a Pt:ITO co-sputtered nanocomposite strain gage with a quite high gage factor of 26.0 and a TCR of $-79 \mathrm{ppm} / \mathrm{C}$ at $90 \%$ by weight $\mathrm{Pt}$. These films were shown to have discrete Pt and ITO phases as confirmed by EDS with phases on the order of several microns [33]. Ding et. al show a nanolaminated Pt:ITO strain sensor with $+30 \mathrm{ppm} / \mathrm{C}$ TCR at $1200 \mathrm{C}$ with a gage factor of 10 [34]. Gerdes et al. explored the Ag:ITO material system and found a near-zero TCR at about 50 at.\% silver with a 
corresponding gage factor of approximately 2 [35]. These are summarized in table 1. Prior work clearly shows the feasibility of use of a multi-material metal semiconductor system to achieve temperature compensation via minimization of TCR. Efforts of this work will be to explore various other material systems to achieve the same effect. 


\section{EXPERIMENTAL PROCEDURE}

\subsection{Indium Tin Oxide Strain Gauges on Thin Alumna Substrates}

The initial concept was to develop a high-temperature, surface mountable strain gage capable of operating in elevated temperature environments. This involved the fabrication of ITO active strain elements directly on thin alumina sheets. These first attempts utilized 4in x 4xin square lapped and polished 50 micron thick $96 \%$ aluminum oxide substrates provided by Valley Design Corp. Due to their thickness and brittleness, handling during processing lead to consistent substrate breakage leading to investigation of other methods.

A second approach involved high velocity flame sprayed (HVOF) alumina fabricated by Hitec Products Inc. Preparation involved thermal spraying of several hundred micrometers of alumina on a sacrificial aluminum mandrel which after sensor deposition may be removed using potassium hydroxide. Subsequent iterations included a solvent dissolvable phenolic resin sacrificial layer between a steel mandrel and HVOF alumina as a release layer.

Lithographic patterning was utilized to define the various patterns for fabrication for this work. Patterning required sequential rinses of acetone, methanol and de-ionized water followed by drying with nitrogen to remove any oils or contaminants that may affect photoresist adhesion. HVOF Alumina substrates with an organic release layer were instead thoroughly scrubbed with soapy water, rinsed with de-ionized water and dried with nitrogen as the 
organic interface layer is sensitive to solvents. The substrate was placed on a hotplate at $150 \mathrm{C}$ for 5 minutes to allow for desorption of any water before lamination of DuPont Electronic Solutions MX5050 Dry Film Photoresist at 95C. A hotplate post-lamination bake was performed to improve photoresist adhesion at $95 \mathrm{C}$ for 1 minute followed by broadband UV exposure using contact aligner at $60 \mathrm{~mJ} / \mathrm{cm} 2$ while masked with a PET laser photoplot film photomask acquired from JD PhotoData. After resist exposure, a post development bake was performed at $95 \mathrm{C}$ for one minute to improve photoresist adhesion. Development of the photoresist was performed in a beaker using a $3 \%$ solution of potassium carbonate for 60 seconds followed rinsing with deionized water and drying with nitrogen.

ITO strain element deposition was performed using a MRC model 822 sputtering tool with $400 \mathrm{~W}$ RF power at a chamber pressure at $3.3 \mathrm{mTorr}$ with a nominal thickness of 1.5 microns verified by measurement of monitor pyrex glass slides masked with kapton tape. Film thickness was measured using a Sloan Dektak model IIA stylus profilometer. One micrometer thick platinum bond pads were deposited using an MRC 8667 sputtering system with 150W RF power in an argon ambient at 9mTorr with film thickness measured in the way previously described. The devices were soaked in acetone to allow for liftoff of the deposited film from the substrate. Temperature coefficient of resistance for the ITO strain gages were established at temperatures up to $250 \mathrm{C}$ on a hotplate using a four-wire measurement. Constant current was applied using a Kiethley model 224 programmable current source. The 
resistance drop across the device was measured using a Hewlett-Packard model 34401A multimeter. Removal of the HVOF Alumina from the sacrificial aluminum mandrel was performed in a heated potassium hydroxide solution. Removal of the HVOF alumina substrates from the steel mandrels involved 12 hours of soaking in acetone attempting to dissolve the sacrificial phenolic resin layer.

\subsection{Tungsten:ITO and Nickel:ITO Strain Gauges on YSZ Substrates}

An alternative approach to realize surface mountable high-temperature capable substrates was explored using commercially available 40 micron thick 3mol\% yttria-stabilized zirconia substrates provided by EnRG Inc. ITO strain elements were patterned and deposited in a similar way as described previously, but were mounted to a 2in x 2in carrier aluminum oxide sheet using Kapton tape prior to resist application as to minimize handling of the delicate substrate.

Metal-ITO composite sputter targets were produced using conventional powder processing techniques as illustrated in figure 7. Tungsten-ITO and nickel-ITO material systems were investigated in this manner. First, ITO and either tungsten or nickel were weighed and coarsely ground and mixed in a mortar and pestle. The mixture was then loaded into a ball mill with $0.5 \mathrm{~cm}$ diameter aluminum oxide abrasive media while submerged in methanol and was attrition milled for 12 hours to create a homogenous mixture. After milling, the methanol was allowed to evaporate and the powder was forced through a 
series of stainless steel sieves, with the smallest mesh opening size being approximately 50um. The powder was mixed with an aqueous $3 \%$ polyvinylalcohol (PVA) binder solution and was mixed until a viscous thick paste was formed. The required amount of binder added varied considerably depending on the metal to ITO ratio. The composite paste was then loaded into a AISI D2 tool steel 2" diameter pellet pressing die and pressed with approximately 1015 tons to form an approximately $1 / 8$ " thick disc. The discs were removed from the pressing die and baked on a hotplate at $120 \mathrm{C}$ for several hours to remove moisture from the green target. The pressed target was then loaded into a Mellen Microtherm split tube furnace on an aluminum oxide ceramic carrier and sintered at $550 \mathrm{C}$ for 5 hours in a nitrogen ambient. After sintering, the sputter target was bonded to a water-cooled fixture using conductive silver epoxy to allow for efficient cooling during the sputter deposition process. Prior to depositing on a sample, the target was RF sputtered at 50W for two hours, $100 \mathrm{~W}$ for two hours and 150W for 4 hours to remove any surface contaminants and to allow surface composition to equilibrate. Sputtering of the composite targets was done after achieving a base chamber pressure of $2 \mathrm{E}-7$ Torr with a forward voltage of $900 \mathrm{~V}$, a chamber pressure of $9 \mathrm{mTorr}$ in an argon ambient with an anode-cathode distance of approximately 1.5". Films were deposited for a total of 5 hours with a 20 minute pause after every 1 hour of deposition to allow for the substrate and target to cool. Photolithographic patterning and acetone thin film liftoff of the composite strain elements and pad metal is performed as described in previous sections. Micrographs of the 
sputtered composite films were collected using a JEOL 5900 scanning electron microscope (SEM). Energy dispersive x-ray spectroscopy (EDS) at $20.0 \mathrm{kV}$ was used to verify the deposited composite film's elemental composition.

Electrical characterization of the Ni:ITO and W:ITO composite strain gauges involved measurement of TCR, gauge factor at room temperature, and resistance drift at elevated temperatures. For TCR characterization to $400 \mathrm{C}$, a custom made microheater test bed was used and is illustrated in figure 8. Test bed setup was confirmed using a type-K thermocouple. Electrical resistance measurements were made using a Hewlett-Packard model 34401A multimeter. Resistance drift at elevated temperature was evaluated to $800 \mathrm{C}$. Samples were loading into Mellen Microtherm split tube furnace, contacts were made to the device under test using Heraeus C5729 conductive gold paste and 25um thick gold wire. Current was applied to the devices under test using a Kiethley model 224 programmable current source. Voltage and temperature were recorded over time using a Personal DAQ/54 22bit data acquisition module using Personal DaqView software.

Determination of the gauge factor requires mounting individual composite strain gages to a constant strain beam. The design of these constant strain beams is such when cantilever loaded any point along the center axis is strained to the same amount, also allowing for simultaneous characterization of many sensors in single test run. Fabrication of these carrier substrates begins with $4.5 \mathrm{in} . \times 4.5 \mathrm{in} . \times .060 \mathrm{in} 96 \%$ alumina sheets provided by 
Coorstek. These were cut to the desired shape by the URI Water Jet Laboratory. Alumina was chosen as a base substrate material due to its stability in oxidative environments, temperature stability, and CTE matching considerations. 1 um of high purity aluminum oxide was R.F. deposited from a $14 \mathrm{~cm}$ diameter target using a Materials Research Corporation Model 8667 sputtering tool at a power density of $0.807 \mathrm{~W} / \mathrm{cm} 2$ in a pure argon ambient at 9mTorr chamber pressure. Platinum leads were patterned and deposited on the alumina constant strain beams in a method as described previously. Stain elements were annealed at $550 \mathrm{C}$ in a nitrogen ambient for 5 hours to allow for densification of films and reduce defects. Individual W:ITO or Ni:ITO strain gages were then either adhered to the constant strain beams either using cyanoacrylate glue for room temperature measurements or mullite cement provided by Hitec Products Inc. and electrical connections were made from the gauge bond pads to thin film platinum terminals on the constant strain beam using 25um gold wire and Heraeus C5729 conductive gold paste. This assembly is loaded into a custom machined zirconia test fixture shown in figure 8 and is cyclically cantilever loaded to apply the desired amount of strain to sensors mounted on the constant strain beam. This apparatus can be configured in such a way to allow specimens to be strained in either tension or compression. Changes in resistance are measured in the same manner as described previously for resistance drift. 


\subsection{Pd:ITO deposition via planar co-sputtering}

To reduce experiment cycle time, an alternative metal:ITO deposition method was explored involving simultaneous deposition of a $99.99 \%$ high purity $90 \mathrm{wt} \% \ln 3 \mathrm{O} 210 \mathrm{wt} \% \mathrm{SnO} 2$ sputter target and a palladium metal target to produce a composite film. As currently configured, the sputtering voltage is split evenly between the two targets during deposition. For this method, we utilize deposition non-uniformity to generate a composition gradient along the length of a sample. Elemental composition of the various elements on these combinatorial libraries was analyzed using EDS as described previously. Patterning, annealing and electrical characterization of these devices is as described previously.

\subsection{Composite Strain Element Deposition via confocal co-sputtering}

Composite strain gage deposition performed at Lincoln Laboratory first involved YSZ substrate cleaning using an acetone, isopropyl alcohol followed by a deionized water rinse and nitrogen drying. Thin YSZ substrates were temporarily mounted to a silicon wafer carrier using Kapton tape prior to a $150 \mathrm{C}$ dehydration bake for two minutes, spin coating of $A Z$ Chemicals nLOF2020 negative photoresist at 3000 RPM for 30 seconds. The resist was soft-baked at $110 \mathrm{C}$ for 1 minute before direct write exposure using a Heidelberg Instruments MLA 150 Maskless Aligner with a 375nm exposure wavelength at $110 \mathrm{~mJ} / \mathrm{cm} 2$ and -1 defocus. A post development hotplate bake was performed at $110 \mathrm{C}$ for 1 minute followed by development in AZ 300MIF 
developer for 30 seconds, rinsing with deionized water and drying with nitrogen.

Nickel:ITO films were deposited using a Denton Discovery 17 sputter system with confocally arranged with 3 " diameter sputter heads at 30 degrees, allowing for fairly uniform composite film deposition across the 6 inch diameter sample platen. After photolithographic patterning, a stainless steel stencil was used to mask deposition as to allow only an individual strain element to be deposited at any time. Table 2 describes the sputter deposition parameters for the various samples fabricated. Liftoff of the deposited films was performed in acetone.

A titanium/platinum/gold pad metal stack was patterned and deposited to make electrical connection to the previously deposited strain elements. Both titanium and platinum were sputtered at $150 \mathrm{~W}$ DC power with $50 \mathrm{sccm} \mathrm{Ar}$ at $2 \mathrm{mTorr}$, and gold was sputtered at $50 \mathrm{~W}$ DC power with $50 \mathrm{sccm}$ Ar at 2 mTorr. The samples were then annealed at $550 \mathrm{C}$ for 5 hours under 5LPM of high purity nitrogen in a Lindberg/Blue M STF55346 tube furnace to allow for film densification and defect reduction in the deposited composite films.

TCR characterization was performed on a hotplate with a 4 point probe setup to $350 \mathrm{C}$ using a Keithley 2400 source meter . Room temperature gauge factor was by bending the substrate around a fixture of constant radius. These fixtures are shown in figure 9. For these measurements, the arrays of YSZ gauges were broken into individual elements using a razor blade and adhered to a flexible Kapton carrier using cyanoacrylate adhesive. Electrical connects 
were made using $0.5 \mathrm{~mm}$ copper wire and conductive nickel paste. Ni:ITO composite gauge factor was characterized from 338 to 3270 microstrain under compression. Current was applied using a Keithley 2400 source meter while voltage was recorded using a Personal DAQ/54 22bit data acquisition module using Personal DaqView software. Applied strain was determined using a reference foil strain gauge acquired from Micro-Measurements Materials and was applied to the flexible Kapton carrier in a similar manner as described previously.

Film stress measurements were made using a Toho FLX-2320-s thin film stress analyzer. Wafer curvature was measured before film deposition, after deposition, and after film annealing on 2" $<100>$ silicon to determine film stress. Composite resistivity, carrier concentration and mobility were determined using a Lakeshore 8407 Hall Effect Measurement Tool at 1 tesla and measured on Van der Pauw structures defined on silicon substrates with 500nm SiO2 deposited using a Samco PD-200STP plasma enhanced chemical vapor deposition (PECVD) system using a tetraethyl orthosilicate (TEOS) precursor. Contacts were applied to the film using indium. 


\section{RESULTS AND DISCUSSION}

\subsection{Flexible High Temperature Substrate Investigation}

The purpose of this initial study was to investigate the suitability of flexible substrates for fabrication of thin film strain gauges for use at elevated temperatures. Ultimately, application of the strain gauges is aimed to be analogous to the widely used constantan foil strain gauges, though capable of operation at temperatures above $200 \mathrm{C}$, the upper temperature limit of most commercially available foil strain gauges. Criteria for substrate suitability include, temperature stability of the substrate to at least $500 \mathrm{C}$ in an oxidizing ambient, a thin form-factor allowing for minimal surface protrusion, a suitably smooth surface as to allow for use of photolithographic patterning, and should be sufficiently robust as to allow for mounting of the material on a test article with ease and without appreciable risk of substrate failure due to brittleness. The coefficient of expansion (CTE) of the substrate relative to the test article should also be considered as large CTE mismatches will apparent strain due to temperature.

Initial tests involved fabrication of ITO thin film strain elements directly on 50um lapped $96 \%$ alumina sheets with a nominal surface roughness of 15 microinch Raas determined by profilometry. ITO strain elements with a nominal thickness of 1.5 um were successfully fabricated and their temperature coefficient of resistance was evaluated to $250 \mathrm{C}$ showing a linear and repeatable TCR of only $17.7 \mathrm{ppm} / \mathrm{C}$, however handling of these thin brittle 
alumina substrates proved troublesome during fabrication and would be practically quite difficult to use and install in a field environment, prompting investigation of other methods. One of these strain gauges was successfully mounted to a CMC test article and is shown in figure 9.

An alternative to using pre-thinned alumina substrates is deposition of a sufficiently thin suitable material on a sacrificial or temporary carrier substrate. In this manner, one could avoid complications from handling thin and brittle substrates during processing, but after release from the temporary carrier ultimately end up with a suitably thin and flexible strain sensor. High velocity oxy-fuel thermal deposition of alumina was performed on a steel substrate on which ITO strain elements were fabricated with a nominal thickness of $1.5 \mathrm{um}$ and is depicted in figure 10. Surface roughness of the HVOF alumina was suitable for photolithography and thin film deposition. It was then necessary to determine a suitable method for release of the HVOF alumina layer from its carrier steel substrate. A phenolic resin was used as a sacrificial layer between the carrier steel substrate and the HVOF alumina. ITO gauges were successfully fabricated, however exposure to acetone during ITO liftoff caused swelling of the release layer resulting in destruction of the HVOF alumina substrate prompting investigation of other thin, flexible high temperature capable substrates.

Thin yttria-stabilized zirconia substrates were next evaluated in a similar manner. ITO strain elements with a nominal thickness of 1.5 um were deposited in a fashion similar to previously described and are shown in figure 
11. These substrates had a suitably low surface roughness and were quite flexible, able to be bent around tight radii and twisted without mechanical failure. ITO strain elements annealed at $600 \mathrm{C}$ were optically examined and showed no sign of permanent distortion of the substrate or electrical disconnects of the strain gauge, demonstrating YSZ's suitability for elevated temperature operation.

\subsection{Tungsten:ITO and Nickel:ITO Strain Gauges on YSZ Substrates}

Indium tin oxide (ITO) has been demonstrated to be a suitable strain element for high temperature operation due to its high gauge factor and stability in elevated temperature environments. Unfortunately, ITO also exhibits a strong negative temperature coefficient of resistivity, which is undesirable for strain gauge operation at elevated temperatures. A number of methods for temperature compensation have been discussed previously. Codeposition of ITO other materials with a positive TCR is the subject of this study.

A simple mixture rule was applied to determine the composition of tungsten and ITO to be deposited. A composite target consisting of 95 weight percent tungsten and 5 weight percent (90/10) ITO was fabricated as described in the methods section. The target was pre-sputtered for several hours to allow for erosion of the surface atoms in the target material. In this way, only the material intended for the active strain elements was deposited on YSZ substrates. Initial evaluation of these composite strain gages exhibited 
a near-zero TCR of approximately $60 \mathrm{ppm} / \mathrm{C}$, but also showed some hysteresis associated with temperature cycling as well as a rather low gage factor of 1.66-1.91 and a nonlinear response to strain shown in figure 12. It is not all that surprising that a minimal gage factor was observed here as the resulting composition of the strain gage was mostly metal, which typically has gauge factors of less than two. A literature review of this suggests that this hysteretic response is characteristic of tungsten containing elements [36] and the observed hysteresis and minimal gage factor lead me to investigate other refractory metals for this application.

Various ratios of nickel and ITO were then evaluated for their suitability as an elevated temperature strain gage and were prepared in a similar manner as previously described for W:ITO composites. Five compositions within the system nickel: ITO ranging from 20 to $70 \%$ nickel by weight were evaluated for this purpose.

To evaluate gage factor, nanocomposite strain elements were deposited onto ultrathin YSZ substrates that were cemented to an alumina constant strain beam as described previously in the methods section. Figure 4.5 shows a 20 wt $\%$ nickel nanocomposite strain element underwent cyclic tensile strain testing at 550 microstrain with excitation currents of 1,2 and $3 \mathrm{~mA}$. A calculated gage factor of 0.785 was measured for these nanocomposites. Temperature coefficients of resistance were determined for temperatures up to $300 \mathrm{C}$ for these five Ni:ITO nanocomposites and the results are shown in table 3 . While the $60 \mathrm{wt} \%$ nickel based nanocomposite exhibited 
a very low TCR $(+35.3 \mathrm{ppm} / \mathrm{C})$, it is clear that no correlation between TCR and the target material composition was established. This could be due to a number of factors including potential issues with the target fabrication process that make for a less controlled set of experiments leading to more variable results.

During target fabrication a fraction of polyvinyl alcohol solution is added to the slurry before pressing as a binder. This may incorporate a small amount of carbon into the target, leading to a target contaminated with carbon. Sintering of the fabricated targets was performed at $550 \mathrm{C}$ in a nitrogen ambient. It is possible that the PVA binder may not completely undergo pyrolysis reaction, and thus leave carbon contamination.

Another possibility for variability in these experiments is non homogeneity in the target composition. This could be a result of inadequate mixing leading to non-uniform dispersal of $\mathrm{Ni}$ and ITO particles throughout the pressed target, leading to deposited films with an unanticipated composition. A common practice when first using a sputter target that has been exposed to the atmosphere is to perform a so called 'burn-in' sputter run prior to depositing on any sample to remove any surface contaminants such as oils, greases and adsorbed liquids that might have been introduced from handling and to remove any contaminants that may have formed due to exposure to the ambient environment. The burn-in process involves a slow power ramp, ultimately allowing the forward voltage to equilibrate. Several hours of sputtering at 200W RF power was performed prior to deposition of the 
composite on any sample. It is possible that this period of time was not sufficient to allow residues on the surface to sputter away or allow the surface composition of the target to equilibrate, again leading to an unintended composition in the deposited thin film.

Various techniques that could have been performed on either the manufactured composite target or the resulting deposited film to verify composition. Energy dispersive $\mathrm{x}$-ray spectroscopy (EDS) is a common technique available in many scanning electron microscopes that gives semiquantitative compositional information. The accelerating voltage of electrons determines the measurement depth and volume of this technique. At an excitation voltage of $20 \mathrm{kV}$, the interaction depth in pure ITO and pure $\mathrm{Ni}$ are simulated to be approximately $1.6 \mathrm{um}$ and $1 \mathrm{um}$ respectively) as determined using a Monte Carlo electron trajectory program, CASINO. These simulations are shown in figure 13 leading to this analysis only being useful on thin films with grains smaller than $1 \mathrm{um}$ and not the fabricated composite targets that have grains on the order of several hundreds of micrometers. Details of the CASINO simulation are mentioned in the methods section. X-ray fluorescence $(\mathrm{XRF})$ is a non-destructive technique that would be suitable for bulk composition measurements of the sputter targets. Unfortunately, these analysis methods were unavailable for use at the time of this study due to budget constraints. 


\subsection{Pd:ITO Strain Gauges via Planar Co-Sputtering}

To avoid complications and uncertainty that might arise from the previously explored composite target fabrication method: i.e. metal- indium tin oxide powder compacts that were sintered, an alternative method for the fabrication of metal:ITO nanocomposites is using a co-sputtering approach. This method of deposition allows for parallel deposition of a number of varying composition films simultaneously, and as such, drastically reduces the fabrication cycles and deposition time required to explore a wide range of compositions of interest.

For these experiments, palladium and indium tin oxide were deposited simultaneously from separate targets (99.9\% pure). Composition of the deposited film varied as a function of distance between the center point of each target. In this manner, several YSZ substrates were patterned and prepared as previously mentioned and placed between a palladium and 90/10 indium tin oxide target to generate a wide range of film compositions. These films were lifted off and annealed as previously described. Ohmic contacts were made using platinum thin films.

Figure 14 shows weight percent palladium present in the deposited films as measured using EDS. Power was equally distributed between a 4" diameter Pd target and a 6" diameter ITO target by means of a relatively higher power density that was achieved for the smaller 4" diameter Pd target,

increasing its deposition rate relative to the larger ITO target. This and a higher sputter yield of palladium relative to indium oxide (2.39 [37] and 0.6 [38] 
respectively) are responsible for the non-gaussian curve of composition verses distance from target centers. A single sputter deposition yielded an array of 30 individual strain elements with compositions ranging from $15-100 \%$ palladium. TCR for various samples were determined to $200 \mathrm{C}$ and are plotted against composition as shown figure 1415.5 and $20.6 \mathrm{wt} \% \mathrm{Pd}$ compositions are measured to have -32.2 and $59.7 \mathrm{ppm} / \mathrm{C}$ TCR at $200 \mathrm{C}$ respectively, indicating a zero TCR crossing at about $17 \mathrm{wt} \%$ palladium. As expected, TCR gradually increases with increasing palladium content to $2187.5 \mathrm{ppm} / \mathrm{C}$ at $52 \mathrm{wt} \%$ palladium, then gradually decreases to $918.3 \mathrm{ppm} / \mathrm{C}$ at $78.3 \mathrm{wt} \%$ palladium. For higher metallic content films, a more positive TCR is expected, whereas for more semiconducting films (films with higher quantities of ITO) a more negative TCR can be expected.

Composite strain gage resistance at room temperature is plotted against $\mathrm{Pd}$ weight percent in figure 15. As palladium content increases, there is a slight increase in gauge resistance until there is a peak at $25.6 \mathrm{wt} \%$ palladium of 933.06 ohms. Further increasing palladium content drastically reduces the resistance of the composite to a minimum of 164.5 ohms at 63.1 wt $\%$ palladium. This is followed by a further increase in resistance with increasing palladium to a local peak of $483.0 \mathrm{ohms}$ at $78.2 \mathrm{wt} \%$ palladium. These trends suggests that beyond gage this composition, defects and grain boundaries cause these variances in electrical resistance. The sharp decrease in gage resistance from $25.6 \mathrm{wt} \%$ palladium to $63.1 \mathrm{wt} \%$ palladium is likely due to the formation of an increasingly prominent contiguous palladium phase 
in the films, where one might expect lower resistance. The sharp increase in gage resistance from $63.1 \mathrm{wt} \%$ palladium to $78.2 \mathrm{wt} \%$ palladium may indicate a formation of smaller discrete grains, which act as electron scattering sites and reduced mobility of electrons. It should be noted there is inherent film thickness non-uniformity using this deposition approach, and so deconvoluting resistance changes as a result of film thickness from composition or grain structure is difficult. It is also likely there is dependence of TCR on film thickness due to apparent strain caused by CTE mismatch of the nanocomposite thin film relative to the substrate.

An additional complication was later discovered from SEM examination of the deposited Pd:ITO films that were co-sputtered in a planar configuration. Figure 16 shows a representative 200 um width resistor stripe. A significant difference in film morphology is observable across the width of the gage serpentine. EDS analysis performed at various points along this serpentine stripe reveal a significant composition drift along the width of the stripe. Due to the oblique angle of deposition associated with this technique and due to patterning these strain elements with very thick (50um thick) photoresist, significant shadowing occurred, causing these compositional gradients. Results are summarized in table 6 .

\subsection{Composite Strain Element Deposition via confocal co-sputtering}

To account for variation in film properties as a function of film thickness and to avoid sputter chamber geometry effects which lead to local composition 
non-uniformity, it is preferred to use a confocally arranged co-sputtering tool. In this configuration, a number of sputter targets are pointed at a central point and are designed to sputter simultaneously while the sample rotates continuously to generate a uniform composition and thickness of deposited film.

The YSZ substrates were patterned with a negative photoresist and liftoff was used to transfer the strain gage pattern as described in the methods section to pattern arrays of active strain elements. Additional silicon wafers prepared with a $500 \mathrm{~nm}$ thermal oxide film were patterned in a similar manner for thin film resistivity measurements using a Van der Pauw pattern. A shadow mask was to block deposition from many elements while only exposing a single element during a particular deposition. After deposition, the shadow mask was shifted to reveal a different active strain element and the deposition process was repeated using different target powers to yield different film compositions. Fabrication of these arrays in this manner allowed for a single lithographic patterning step to yield a large number of different composition strain gages via sequential depositions. A nanocomposite film thickness of 0.5um was targeted for initial evaluation of the nickel indium tin oxide material system. This composition was determined using EDS and the results are presented in table 4 for films deposited on silicon substrates, and in table 5 for films deposited on YSZ substrates. Note that overall film thickness is not constant for all measurements, since an incorrect deposition rate verses power curve for nickel was initially used during initial depositions on silicon 
substrates. Figure 17 shows measured film stress after deposition as a function of increasing nickel content. It is noted that films become increasingly compressive at low nickel contents until approximately $30 \mathrm{wt} \%$ nickel, after which there is a sharp decrease in stress at $40 \mathrm{wt} \%$ nickel. This decrease was followed by a sharp increase in compressive stress until $75 \mathrm{wt} \% \mathrm{Ni}$, after which film stress appears to relax with increasing nickel content. Film resistivity was immediately measured post deposition using a four point probe technique. A 15 fold increase in sheet resistance is observed with only 5.5 wt\% nickel in the nanocomposite as compared to pure ITO, after which a logarithmic decrease in sheet resistance was observed. The sharp increase in unannealed film sheet resistance at very low nickel contents may be the result of reduced carrier mobility as a result of increased grain boundary density associated with the small nickel inclusions. As the nickel content increased, it is likely that grain growth of the nickel occurred, decreasing grain boundary density and reducing resistivity. Films were also deposited on thin YSZ using corrected deposition rates. These films were later annealed at $550 \mathrm{C}$ in $\mathrm{N}_{2}$ to promote defect and stress reduction in the deposited film.

The TCR of the Ni:ITO nanocomposites were experimentally determined at temperatures up to $350 \mathrm{C}$ and are plotted in figure $18 \mathrm{a}$ and tabulated in table 7. Pure indium tin oxide films exhibited a slightly negative TCR of $-270.8 \mathrm{ppm} / \mathrm{C}$. Increasing nickel content raised the TCR from 270.8 to $289 \mathrm{ppm} / \mathrm{C}$ at $5.5 \%$ by weight nickel, where a gradual decrease to $-110 \mathrm{ppm} / \mathrm{C}$ was observed for nanocomposites with $21.1 \mathrm{wt} \%$ nickel. It is interesting to note 
that for these samples, an increase in nickel content to approximately 20 weight percent had a rather small impact on TCR of the measured film. This could be due to nickel scavenging oxygen from $\mathrm{In}_{2} \mathrm{O}_{3}$ and $\mathrm{SnO}_{2}$ film via a displacement reaction, forming a p-type conductive oxide where carriers annihilate, as to not contribute largely to TCR. An increase in sheet resistance is also observed in this regime which may also support this hypothesis. With further increasing nickel content, a strong increase in TCR was observed in the $52.1 \mathrm{wt} \%$ nickel films having a TCR of $4839.1 \mathrm{ppm} / \mathrm{C}$. This rise in TCR with increasing nickel content was anticipated and suggests the formation of a contiguous nickel phase, where the TCR approaches that of bulk nickel and the film properties become more metallic.

Room temperature gage factor was determined by 4 pt bending the Ni:ITO strain gages on plastic forms of constant radii to induce strain. The gage factor was determined to be nearly linear with increasing compressive strain as shown in figure $18 \mathrm{~b}$ and is plotted verses composition in figure $18 \mathrm{c}$. All compositions tested showed a rather low gage factor of less than 2 .

To begin to investigate the microstructure of the nanocomposites, Ni:ITO co-sputtered films were deposited on $<100>$ silicon and cleaved to produce cross sections analyzed using secondary electron scanning electron microscopy (SEM) and are shown in figure 19. As expected, a densified, largely columnar film structure was observed, as predicted from Thorton Zone models, in that these films were deposited at essentially room temperature and a low pressure of 2 mTorr. Interestingly, pure ITO grains grown at these 
conditions appear to exhibit competitive growth. This is unexpected as one would only expect competitive growth at rather high temperatures relative to the deposited material melting point. ITO has a melting point of approximately 1900C [39], and the surface temperature during deposition likely doesn't exceed 100C. Cross sectional secondary electron SEM of films with increasing metal content show less competitive growth behavior and also appear to fracture in a more ductile fashion, as expected with more metallic films. A collage of various compositions is shown in figure 22 as deposited on YSZ substrates from the top down. Note that the larger scale roughness observed is the topology of the YSZ substrates. Here, a light speckle pattern was observed that becomes more prominent in higher weight percent nickel nanocomposite films. This initially suggested that segregation of the nickel phase from the ITO matrix phase was possible. Interestingly enough, additional examination of these samples using backscattered SEM, indicated that the jagged precipitates were the same material as the bulk film (since atomic number of the constituents determines contrast in backscattered SEM). Further analysis using low-energy EDS mapping at $1.5 \mathrm{kV}$ also showed little compositional difference between these particles and the bulk film at high magnification. Monte-Carlo simulation suggests that a typical interaction volume of roughly $10 \mathrm{~nm}^{3}$ at this energy, which further suggests either metallic $\mathrm{Ni}$ and ITO are soluble in one another and form a single miscible phase, or distinct phases of ITO and Ni have grain sizes smaller than 10nm and therefore, are not distinguishable using SEM. A different analytical method 
using high resolution transmission electron microscopy would be needed for grain size analysis and to determine the nanoscale morphology of these films.

Figure 23 shows measured film resistivity, charge carrier concentration and carrier mobility measured using Hall measurements of the films with varying nickel content. Pure ITO exhibits a negative hall voltage, indicating ntype semiconducting behavior as expected. Sheet resistivity of these Ni:ITO nanocomposite films appears to increase with increasing nickel content, which is apparently caused by the marked decrease in carrier concentration and an increase in carrier mobility until the films contained $20 \%$ wt. $\%$ nickel. This is not intuitive, as one might expect the opposite trend where bulk metals have a substantially higher carrier concentration (as calculated by a simple Drude carrier model), and accompanied by a decrease in Hall mobility due to presumably smaller grain sizes associated with Ni or ITO deposition that could hamper grain growth. In any case, there is a rolling off in carrier concentration and Hall mobility with increasing nickel content beyond $20 \mathrm{wt} \%$ nickel, which suggests conduction through the nickel is dominating and correlates well with the observed trend in TCR as noted earlier. If films with metal content greater than $80 w t \%$ were analyzed, it might provide valuable insight and may help explain these observed phenomena. 


\section{CONCLUSION AND FUTURE WORK}

\subsection{Conclusions}

A number of refractory metal nanocomposites were prepared with ITO continuous phases were fabricated with the intent to achieve self-temperature compensation in a single active strain gage element. Tungsten:indium-tinoxide composites were fabricated via powder processing to produce composite targets with a nominal composition of $95 \mathrm{wt} . \%$ tungsten. These showed a relatively small TCR of about $60 \mathrm{ppm} / \mathrm{C}$, but also showed a small non-linear gage factor of less than two with considerable hysteresis when thermally cycled to temperatures below 400C. Ni:ITO composites were fabricated in a similar manner. A 60 wt.\% Ni:ITO nanocomposite film exhibited a small TCR of only $35.3 \mathrm{ppm} / \mathrm{C}$ and a gage factor of $<2$. Nanocomposites based on other Ni:ITO compositions were evaluated in terms of TCR with no clear relationship observed between nickel content and TCR. This is believed to be the result of poorly fabricated composite targets and either contamination of the source target with carbon due to unpyrolyzed PVA binder, or deposition of strain gages from targets whose surface composition had not reached the bulk concentration, or non-homogenous bulk composition in the fabricated targets, all of which could lead to "alloys" of unknown composition.

To address these issues, the planar co-sputtering of Pd:ITO alloys was investigated. Here, a number of Pd:ITO nanocomposite films were fabricated and TCR was measured as a function of composition. There was a "zero 
crossing" at approximately 15 wt. \% Pd in the nanocomposite. Here, TCR increased to about $2200 \mathrm{ppm} / \mathrm{C}$ at $50 \mathrm{wt} \% \mathrm{Pd}$ before dropping to $1000 \mathrm{ppm} / \mathrm{C}$ at almost $80 \mathrm{wt} . \% \mathrm{Pd}$. This was also accompanied by an increase in electrical resistance at higher $\mathrm{Pd}$ content, which may suggest that even if the palladium phase becomes contiguous at these higher concentrations, the excess ITO in the films dominates the electrical conductivity. Additional experiments using higher Pd contents would support this theory. It also was noticed that micromasking of these patterned sensors caused compositional gradients across the patterned strain gages due to the oblique angle of deposition and relatively thick photoresist used for liftoff (50um). This along with variable film thickness as a result of inherent deposition rate non-uniformities due to the planar cosputtering deposition method and a clear dependence on TCR as a function of film thickness make the mechanisms for this electrical behavior difficult to interpret.

Finally, confocal co-sputtering of Ni:ITO nanocomposites was investigated to fabricate temperature compensated strain gages. These nanocomposite films exhibited near zero TCR for a wide range of Ni:ITO compositions until approximately $20 \mathrm{wt} . \% \mathrm{Ni}$, with compressive gage factors ranging from 0.69 to 1.70. Beyond $20 \%$ wt. nickel, an inflection in TCR was observed and Hall measurements revealed that the carrier mobility and carrier concentration did not change significantly beyond this metal content in the films.

A number of different refractory metal:ITO systems were investigated using a number of fabrication methods. Near-zero TCR was observed at 
approximately $95 \%$ wt. $\%$ tungsten in the W:ITO system. A TCR of +35.3 $\mathrm{ppm} / \mathrm{C}$ was observed for a $60 \mathrm{wt} \%$ nickel composite when fabricated using a powder processed composite target, and a TCR of $-32.2 \mathrm{ppm} / \mathrm{C}$ was observed for a 17 wt. \% palladium nanocomposite using a planar co-sputtering process, and near zero TCR was observed for a $20 \mathrm{wt} \%$ nickel nanocomposite using a confocally focused co-sputtering technique. Unfortunately, there are some discrepancies in the measured data. For example, the discrepancy between the zero-TCR composition mismatch between confocally co-sputtered Ni:ITO nanocomposites compared to those prepared from a powder processed composite target. As discussed at length in the section 4.3, this difference is likely due to either the variation in composition throughout the sintered target (compact), incorporation of impurities during powder processing and other non-homogeneities related to the fabrication the composite targets such as density gradients due to pressing. Additionally, it should be noted that the method and deposition conditions used for the different types of experiments differ significantly. Diode RF sputtering was used for the initial Ni:ITO composite work, and magnetron DC for the confocally co-sputtered work. These depositions were performed at different power densities and at different chamber pressures which certainly influence the deposited film properties. Another note is that TCR verses composition curves for the confocally cosputtered Ni:ITO nanocomposites were different from the Pd:ITO nanocomposites produced from the planar system. The TCR of the Pd:ITO nanocomposites was evaluated for the $80 \mathrm{wt} \% \mathrm{Pd}$ composition, however for the 
confocally co-sputtered Ni:ITO films, the TCR was only evaluated to $50 \mathrm{wt} \%$, so it's possible a similar trend observed in the TCR behavior of high metal content samples in the Pd:ITO may be observed in these Ni:ITO composite films with high Ni content.

\subsection{Future Work}

These initial results of exploration of the W:ITO, Pd:ITO and Ni:ITO material systems for achieving temperature compensation are quite promising. Additional work should be performed to evaluate fundamental characteristics of these strain gauges- resistance drift at elevated temperatures and gauge factor at elevated temperatures to be able to fully compare the performance to conventional $\mathrm{NiCr}$ or $\mathrm{PdCr}$ strain gauges. Investigation of the effect of different process parameters and their effect on TCR and gauge factor should also be considered. Literature suggests there is a strong relationship between gauge factors of deposited films with applied substrate bias and by choice of deposition pressure [40] and so consideration of these parameters is likely

necessary for film property optimization. Exploration of the effect of deposition temperature, annealing temperature and anneal ambient on resulting film properties would also be quite insightful on observing the effect of film morphology on observed film properties such as gage factor and TCR. Comparison of the morphology of composite films generated in this study to temperature compensated Pt:ITO films demonstrated by Gregory et al. [34], shows a significant difference in as-annealed film morphology. Gregory's work 
showed discrete Pt and ITO phases with a typical grain size on the order of several micrometers, whereas in this work, composite films had either no discernable phases or grains less than $10-20 \mathrm{~nm}$ in diameter. Investigation into the differences between the difference in film structure and the resulting film characteristics would be insightful. Ultimately, discerning the effects between temperature dependent geometric or film stress related effects due to the composite CTE of the deposited film verses inherent changes in the mechanism of conductivity in as a function of composition or temperature will for a better understanding of these nanocomposite systems and allow for tailor-made materials with optimized properties. 


\section{REFERENCES}

1. Sharma, Surender Kumar. Handbook of Materials Characterization. Springer, 2018.

2. Kracke, Art. "Superalloys, the Most Successful Alloy System of Modern Times-Past, Present, and Future." Superalloy 718 and Derivatives, John Wiley \& Sons, Inc., 2012, pp. 13-50, http://dx.doi.org/10.1002/9781118495223.ch2.

3. Schafrik, R. E., and Scott Walston. "Challenges for High Temperature Materials in the New Millenium." The Minerals, Metls \& Materials Society, 2008.

4. Clarke, David R., and Simon R. Phillpot. "Thermal Barrier Coating Materials." Materials Today, no. 6, Elsevier BV, June 2005, pp. 22-29. Crossref, doi:10.1016/s1369-7021(05)70934-2.

5. Gregory, Otto J., Gustave C. Fralick, et al. "Nano-Composites for Thermal Barrier Coatings and Thermo-Electric Energy Generators." US20090290614A1, United States Patent and Trademark Office , July 2014. "NANO-COMPOSITES FOR THERMAL BARRIER COATINGS AND THERMO-ELECTRIC ENERGY GENERATORS ." US20090290614A1, United States Patent and Trademark Office, Nov. 2009.

6. Glass, David E. "Thermal Protection Systems and Hot Structures for Hypersonic Vehicles." Aerospace Materials and Applications, American 
Institute of Aeronautics and Astronautics, Inc., 2018, pp. 531-78, http://dx.doi.org/10.2514/5.9781624104893.0531.0578.

7. NASA. NASA Tech Briefs, February 2011 - Vol 35 No. 2. Feb. 2011.

8. "Product Information Hoskins, HBWAH Series Strain Gage." Hitec Products, Inc., 26 Mar. 2021, https://hitecprod.com/hpi_products/hoskins-hbwah-series.

9. Wrbanek, John D., et al. "Ceramic Thin Film Thermocouples for SiCBased Ceramic Matrix Composites." Thin Solid Films, no. 17, Elsevier BV, June 2012, pp. 5801-06. Crossref, doi:10.1016/j.tsf.2012.04.034.

10. Luo, Qing. "Indium Tin Oxide Thin Film Strain Gages for Use at Elevated Temperatures." Disserations and Master's Theses (Campus Access), 2001.

11. Kayser, P., et al. "High-Temperature Thin-Film Strain Gauges." Sensors and Actuators A: Physical, Elsevier BV, June 1993, pp. 328-32. Crossref, doi:10.1016/0924-4247(93)80055-I.

12. Thomson, William. "ON THE ELECTRO-DYNAMIC QUALITIES OF METALS. [THE BAKERIAN LECTURE]." Mathematical and Physical Papers, Cambridge University Press, pp. 189-407, http://dx.doi.org/10.1017/cbo9780511996016.027.US2340146A US

13. Ruge, Arthur C. "Strain Gauge." US2350972A, United States Patent and Trademark Office, Sept. 1939.

14. Reed, and Hannah. Strain Gage Users' Handbook. Springer Science \& Business Media, 1992. 
15. Kouroussis, Georges, et al. "Review of Trackside Monitoring Solutions: From Strain Gages to Optical Fibre Sensors." Sensors, no. 8, MDPI AG, Aug. 2015, pp. 20115-39. Crossref, doi:10.3390/s150820115.

16. Yanada, T., et al. "Earthquake Sensor." Sensors Update, no. 1, Wiley, Dec. 2002, pp. 159-216. Crossref, doi:10.1002/seup.200211101.Strain gauge analysis of occlusal forces on implant prostheses

17. Kazi, Imam H., et al. "The Electromechanical Behavior of Nichrome (80/20 Wt.\%) Film." Thin Solid Films, no. 1-2, Elsevier BV, June 2003, pp. 337-43. Crossref, doi:10.1016/s0040-6090(03)00390-0.

18. Smith, Charles S. "Piezoresistance Effect in Germanium and Silicon." Physical Review, no. 1, American Physical Society (APS), Apr. 1954, pp. 42-49. Crossref, doi:10.1103/physrev.94.42.

19. Barlian, A. A., et al. "Review: Semiconductor Piezoresistance for Microsystems." Proceedings of the IEEE, no. 3, Institute of Electrical and Electronics Engineers (IEEE), Mar. 2009, pp. 513-52. Crossref, doi:10.1109/jproc.2009.2013612.

20. Navick, X. F., et al. "Fabrication of Ultra-Low Radioactivity Detector Holders for Edelweiss-II." Nuclear Instruments and Methods in Physics Research Section A: Accelerators, Spectrometers, Detectors and Associated Equipment, no. 1-3, Elsevier BV, Mar. 2004, pp. 189-92. Crossref, doi:10.1016/j.nima.2003.11.290. 
21. Tong, Lizhen, and Jinxing Guo. "Noble Metal Alloys as Strain Gauge Materials." Platinum Metals Review, Johnson Matthey Public Limited Company, 1994.

22. Lei, Jih-Fen, and Herbert A. Will. "Thin-Film Thermocouples and StrainGauge Technologies for Engine Applications." Sensors and Actuators A: Physical, no. 2-3, Elsevier BV, Mar. 1998, pp. 187-93. Crossref, doi:10.1016/s0924-4247(97)01683-x.

23. Dyer, S. E., O. J. Gregory, and J. D. Cooke. "Improved Passivating Cr2O3 Scales for Thin Film High Temperature PdCr Strain Gages." Thin Solid Films, no. 1-2, Elsevier BV, Jan. 1998, pp. 331-40. Crossref, doi:10.1016/s0040-6090(97)00689-5.

24. Gregory, Otto J., Qing Luo, et al. "High Temperature Stability of Indium Tin Oxide Thin Films." Thin Solid Films, no. 1-2, Elsevier BV, Mar. 2002, pp. 286-93. Crossref, doi:10.1016/s0040-6090(01)01773-4.

25. Dyer, S. E., O. J. Gregory, P. S. Amons, et al. "Preparation and Piezoresistive Properties of Reactively Sputtered Indium Tin Oxide Thin Films." Thin Solid Films, no. 1-2, Elsevier BV, Nov. 1996, pp. 279-86. Crossref, doi:10.1016/s0040-6090(96)08865-7.

26. (Polymer Nanoclay Composites) Aruchamy, Kanakaraj, et al. "Electrospun Nanofibers, Nanocomposites and Characterization of Art: Insight on Establishing Fibers as Product." Nano-Structures \& NanoObjects, Elsevier BV, Oct. 2018, pp. 45-58. Crossref, doi:10.1016/j.nanoso.2018.03.013. 
27. "Strain Sensing Polymer Nanocomposites at Ultralow Graphene Loading Level." ECS Meeting Abstracts, The Electrochemical Society, 2016. Crossref, doi:10.1149/ma2016-02/8/1058.

28. Barshilia, Harish C., et al. "Structure and Optical Properties of AgAl2O3 Nanocermet Solar Selective Coatings Prepared Using Unbalanced Magnetron Sputtering." Solar Energy Materials and Solar Cells, no. 7, Elsevier BV, July 2011, pp. 1707-15. Crossref, doi:10.1016/j.solmat.2011.01.034.

29. Ghanekar, Alok, et al. "Photonic Metamaterials: Controlling Nanoscale Radiative Thermal Transport." Heat Transfer - Models, Methods and Applications, InTech, 2018, http://dx.doi.org/10.5772/intechopen.72805.

30. Gregory, Otto J., Gustave C. Fralick, et al. "Nano-Composites for Thermal Barrier Coatings and Thermo-Electric Energy Generators." US20090290614A1, United States Patent and Trademark Office , July 2014 ---. "NANO-COMPOSITES FOR THERMAL BARRIER COATINGS AND THERMO-ELECTRIC ENERGY GENERATORS ." US20090290614A1, United States Patent and Trademark Office, Nov. 2009.

31. Rafiee, Mohammad A., et al. "Enhanced Mechanical Properties of Nanocomposites at Low Graphene Content." ACS Nano, no. 12, American Chemical Society (ACS), Dec. 2009, pp. 3884-90. Crossref, doi:10.1021/nn9010472. 
32. Hu, Bin, et al. "Conductive PVDF-HFP/CNT Composites for Strain Sensing." Functional Materials Letters, no. 02, World Scientific Pub Co Pte Lt, Apr. 2016, p. 1650024. Crossref, doi:10.1142/s1793604716500247.

33. Chen, Ximing, and Ximing Chen. "ITO-Nanocomposite Thin Film Strain Gages with Low TCR." MRS Proceedings, Springer Science and Business Media LLC, 2007. Crossref, doi:10.1557/proc-1024-a05-06.

34. Yang, Shenyong, et al. "In-Situ Self-Compensated Pt-ITO Thin Film Strain Gage with a Nanolaminated Structure." 2019 20th International Conference on Solid-State Sensorsm Actuators and Microsystems \& Eurosensors XXXIII (TRANSDUCERS \& EUROSENSORS XXXIII), June 2019.

35. Gerdes, Holger, et al. "Sputter Deposition of Strain Gauges Using ITO/Ag." Plasma Processes and Polymers, no. S1, Wiley, May 2009, pp. S813-16. Crossref, doi:10.1002/ppap.200932101.

36. Verrilli, Michael J., et al. "High Temperature Fatigue Behavior of Tungsten Copper Composites." NASA Technical Memorandum, Oct. 2004.

37. Wasa, Kiyotaka. "Sputtering Phenomena." Handbook of Sputtering Technology, Elsevier, 2012, pp. 41-75, http://dx.doi.org/10.1016/b9781-4377-3483-6.00002-4.

38. Li, Hu, et al. "Sputtering Yields and Surface Chemical Modification of Tin-Doped Indium Oxide in Hydrocarbon-Based Plasma Etching." 
Journal of Vacuum Science \& Technology A: Vacuum, Surfaces, and Films, no. 6, American Vacuum Society, Nov. 2015, p. 060606. Crossref, doi:10.1116/1.4927125.

39. Gregory, Otto J., Qing Luo, et al. "High Temperature Stability of Indium Tin Oxide Thin Films." Thin Solid Films, no. 1-2, Elsevier BV, Mar. 2002, pp. 286-93. Crossref, doi:10.1016/s0040-6090(01)01773-4.

40. Heckmann, U., et al. "New Materials for Sputtered Strain Gauges." Procedia Chemistry, no. 1, Elsevier BV, Sept. 2009, pp. 64-67. Crossref, doi:10.1016/j.proche.2009.07.016.

41. "File:StrainGaugeVisualization.svg -Wikimedia Commons" [Online]. Available:https://commons.wikimedia.org/wiki/File:StrainGaugeVisualiza tion.svg. [Accessed: 21-Apr-2021].

42. "File: Sputter_Process_Trend_Chart.jpg" [Online]. Available: https://Infwiki.eecs.umich.edu/wiki/images/4/4e/Sputter_Process_Trend_Chart.jp g [Accessed:21-Apr-2021].

43. Charpentier, C., et al. "X-Ray Diffraction and Raman Spectroscopy for a Better Understanding of ZnO:Al Growth Process." EPJ Photovoltaics, EDP Sciences, 2011, p. 25002. Crossref, doi:10.1051/epjpv/2011026.

44. Dujavová, A., et al. "TI-Based Patterned Superconducting Structures: Fabrication and Study." Superconductor Science and Technology, no. 4, IOP Publishing, Mar. 2010, p. 045007. Crossref, doi:10.1088/09532048/23/4/045007. 
45. Werner, Florian. "Hall Measurements on Low-Mobility Thin Films." Journal of Applied Physics, no. 13, AIP Publishing, Oct. 2017, p. 135306. Crossref, doi:10.1063/1.4990470. 


\section{BIBLIOGRAPHY}

Aruchamy, Kanakaraj, et al. "Electrospun Nanofibers, Nanocomposites and Characterization of Art: Insight on Establishing Fibers as Product." Nano-Structures \& Nano-Objects, Elsevier BV, Oct. 2018, pp. 45-58. Crossref, doi:10.1016/j.nanoso.2018.03.013.

Barlian, A. A., et al. "Review: Semiconductor Piezoresistance for Microsystems." Proceedings of the IEEE, no. 3, Institute of Electrical and Electronics Engineers (IEEE), Mar. 2009, pp. 513-52. Crossref, doi:10.1109/jproc.2009.2013612.

Barshilia, Harish C., et al. "Structure and Optical Properties of Ag-Al2O3 Nanocermet Solar Selective Coatings Prepared Using Unbalanced Magnetron Sputtering." Solar Energy Materials and Solar Cells, no. 7, Elsevier BV, July 2011, pp. 1707-15. Crossref, doi:10.1016/j.solmat.2011.01.034.

Chen, Ximing, and Ximing Chen. "ITO-Nanocomposite Thin Film Strain Gages with Low TCR." MRS Proceedings, Springer Science and Business Media LLC, 2007. Crossref, doi:10.1557/proc-1024-a05-06.

Charpentier, C., et al. "X-Ray Diffraction and Raman Spectroscopy for a Better Understanding of ZnO:Al Growth Process." EPJ Photovoltaics, EDP Sciences, 2011, p. 25002. Crossref, doi:10.1051/epjpv/2011026.

Cho, Young-Eun, et al. "Strain Gauge Analysis of Occlusal Forces on Implant Prostheses at Various Occlusal Heights." The International Journal of 
Oral \& Maxillofacial Implants, no. 5, Quintessence Publishing, Sept. 2014, pp. 1034-41. Crossref, doi:10.11607/jomi.3040.

Clarke, David R., and Simon R. Phillpot. "Thermal Barrier Coating Materials." Materials Today, no. 6, Elsevier BV, June 2005, pp. 22-29. Crossref, doi:10.1016/s1369-7021(05)70934-2.

Dujavová, A., et al. "Tl-Based Patterned Superconducting Structures:

Fabrication and Study." Superconductor Science and Technology, no.

4, IOP Publishing, Mar. 2010, p. 045007. Crossref, doi:10.1088/09532048/23/4/045007.

Dyer, S. E., O. J. Gregory, and J. D. Cooke. "Improved Passivating Cr2O3 Scales for Thin Film High Temperature PdCr Strain Gages." Thin Solid Films, no. 1-2, Elsevier BV, Jan. 1998, pp. 331-40. Crossref, doi:10.1016/s0040-6090(97)00689-5.

Dyer, S. E., O. J. Gregory, P. S. Amons, et al. "Preparation and Piezoresistive Properties of Reactively Sputtered Indium Tin Oxide Thin Films." Thin Solid Films, no. 1-2, Elsevier BV, Nov. 1996, pp. 279-86. Crossref, doi:10.1016/s0040-6090(96)08865-7.

Gerdes, Holger, et al. "Sputter Deposition of Strain Gauges Using ITO/Ag." Plasma Processes and Polymers, no. S1, Wiley, May 2009, pp. S81316. Crossref, doi:10.1002/ppap.200932101.

Ghanekar, Alok, et al. "Photonic Metamaterials: Controlling Nanoscale Radiative Thermal Transport." Heat Transfer - Models, Methods and Applications, InTech, 2018, http://dx.doi.org/10.5772/intechopen.72805. 
Glass, David E. "Thermal Protection Systems and Hot Structures for Hypersonic Vehicles." Aerospace Materials and Applications, American Institute of Aeronautics and Astronautics, Inc., 2018, pp. 531-78, http://dx.doi.org/10.2514/5.9781624104893.0531.0578.

Gregory, Otto J., Qing Luo, et al. "High Temperature Stability of Indium Tin Oxide Thin Films." Thin Solid Films, no. 1-2, Elsevier BV, Mar. 2002, pp. 286-93. Crossref, doi:10.1016/s0040-6090(01)01773-4.

Gregory, Otto J., Gustave C. Fralick, et al. "Nano-Composites for Thermal Barrier Coatings and Thermo-Electric Energy Generators." US20090290614A1, United States Patent and Trademark Office, July 2014.

---. "NANO-COMPOSITES FOR THERMAL BARRIER COATINGS AND THERMO-ELECTRIC ENERGY GENERATORS ." US20090290614A1, United States Patent and Trademark Office, Nov. 2009.

Heckmann, U., et al. "New Materials for Sputtered Strain Gauges." Procedia Chemistry, no. 1, Elsevier BV, Sept. 2009, pp. 64-67. Crossref, doi:10.1016/j.proche.2009.07.016.

Kayser, P., et al. "High-Temperature Thin-Film Strain Gauges." Sensors and Actuators A: Physical, Elsevier BV, June 1993, pp. 328-32. Crossref, doi:10.1016/0924-4247(93)80055-I.

Kazi, Imam H., et al. "The Electromechanical Behavior of Nichrome (80/20 Wt.\%) Film." Thin Solid Films, no. 1-2, Elsevier BV, June 2003, pp. 337-43. Crossref, doi:10.1016/s0040-6090(03)00390-0. 
Kouroussis, Georges, et al. "Review of Trackside Monitoring Solutions: From Strain Gages to Optical Fibre Sensors." Sensors, no. 8, MDPI AG, Aug. 2015, pp. 20115-39. Crossref, doi:10.3390/s150820115.

Kracke, Art. "Superalloys, the Most Successful Alloy System of Modern TimesPast, Present, and Future." Superalloy 718 and Derivatives, John Wiley \& Sons, Inc., 2012, pp. 13-50, http://dx.doi.org/10.1002/9781118495223.ch2.

Lei, Jih-Fen, and Herbert A. Will. "Thin-Film Thermocouples and Strain-Gauge Technologies for Engine Applications." Sensors and Actuators A: Physical, no. 2-3, Elsevier BV, Mar. 1998, pp. 187-93. Crossref, doi:10.1016/s0924-4247(97)01683-x.

$\mathrm{Li}, \mathrm{Hu}$, et al. "Sputtering Yields and Surface Chemical Modification of TinDoped Indium Oxide in Hydrocarbon-Based Plasma Etching." Journal of Vacuum Science \& Technology A: Vacuum, Surfaces, and Films, no. 6, American Vacuum Society, Nov. 2015, p. 060606. Crossref, doi:10.1116/1.4927125.

Luo, Qing. "Indium Tin Oxide Thin Film Strain Gages for Use at Elevated Temperatures." Disserations and Master's Theses (Campus Access), 2001.

Paper AAl3025561. https://digitalcommons.uri.edu/dissertations/AAI3025561

NASA. NASA Tech Briefs, February 2011 - Vol 35 No. 2. Feb. 2011.

Navick, X. F., et al. "Fabrication of Ultra-Low Radioactivity Detector Holders for Edelweiss-II." Nuclear Instruments and Methods in Physics Research 
Section A: Accelerators, Spectrometers, Detectors and Associated Equipment, no. 1-3, Elsevier BV, Mar. 2004, pp. 189-92. Crossref, doi:10.1016/j.nima.2003.11.290.

Predel, B. "Pt-W (Platinum-Tungsten)." Ni-Np - Pt-Zr, Springer-Verlag, pp. 12, http://dx.doi.org/10.1007/10542753_2538.

"Product Information Hoskins, HBWAH Series Strain Gage." Hitec Products, Inc., 26 Mar. 2021, https://hitecprod.com/hpi_products/hoskins-hbwahseries.

Rafiee, Mohammad A., et al. "Enhanced Mechanical Properties of Nanocomposites at Low Graphene Content." ACS Nano, no. 12, American Chemical Society (ACS), Dec. 2009, pp. 3884-90. Crossref, doi:10.1021/nn9010472.

Reed, and Hannah. Strain Gage Users' Handbook. Springer Science \& Business Media, 1992.

Ruge, Arthur C. "Strain Gauge." US2350972A, United States Patent and Trademark Office, Sept. 1939.

Schafrik, R. E., and Scott Walston. "Challenges for High Temperature Materials in the New Millenium." The Minerals, Metls \& Materials Society, 2008.

Sharma, Surender Kumar. Handbook of Materials Characterization. Springer, 2018. 
Smith, Charles S. "Piezoresistance Effect in Germanium and Silicon." Physical Review, no. 1, American Physical Society (APS), Apr. 1954, pp. 42-49. Crossref, doi:10.1103/physrev.94.42.

"Strain Sensing Polymer Nanocomposites at Ultralow Graphene Loading Level." ECS Meeting Abstracts, The Electrochemical Society, 2016. Crossref, doi:10.1149/ma2016-02/8/1058.

Thomson, William. "ON THE ELECTRO-DYNAMIC QUALITIES OF METALS. [THE BAKERIAN LECTURE]." Mathematical and Physical Papers, Cambridge University Press, pp. 189-407, http://dx.doi.org/10.1017/cbo9780511996016.027.

Verrilli, Michael J., et al. "High Temperature Fatigue Behavior of Tungsten Copper Composites." NASA Technical Memorandum, Oct. 2004.

Wasa, Kiyotaka. "Sputtering Phenomena." Handbook of Sputtering Technology, Elsevier, 2012, pp. 41-75, http://dx.doi.org/10.1016/b9781-4377-3483-6.00002-4.

Werner, Florian. "Hall Measurements on Low-Mobility Thin Films." Journal of Applied Physics, no. 13, AIP Publishing, Oct. 2017, p. 135306. Crossref, doi:10.1063/1.4990470.

Wrbanek, John D., et al. "Ceramic Thin Film Thermocouples for SiC-Based Ceramic Matrix Composites." Thin Solid Films, no. 17, Elsevier BV, June 2012, pp. 5801-06. Crossref, doi:10.1016/j.tsf.2012.04.034.

Yanada, T., et al. "Earthquake Sensor." Sensors Update, no. 1, Wiley, Dec. 2002, pp. 159-216. Crossref, doi:10.1002/seup.200211101. 
Yang, Shenyong, et al. "In-Situ Self-Compensated Pt-ITO Thin Film Strain Gage with a Nanolaminated Structure." 2019 20th International Conference on Solid-State Sensorsm Actuators and Microsystems \& Eurosensors XXXIII (TRANSDUCERS \& EUROSENSORS XXXIII), June 2019. 
Appendix Tables and figures:

Material 
Element 
Wt. \% Pd 
Wt. \% Ni 
Figure 1. Influence of compressive and tensile strain on a typical metal foil strain gauge [41]. 
Figure 2. Schematic illustration of a planar configured co-sputtering system

Figure 2. Schematic illustration of a confocally arranged co-sputtering system. 
Figure 3. Film characteristics as a function of deposition parameters [42]

Figure 4. Thornton film growth zones [43] 


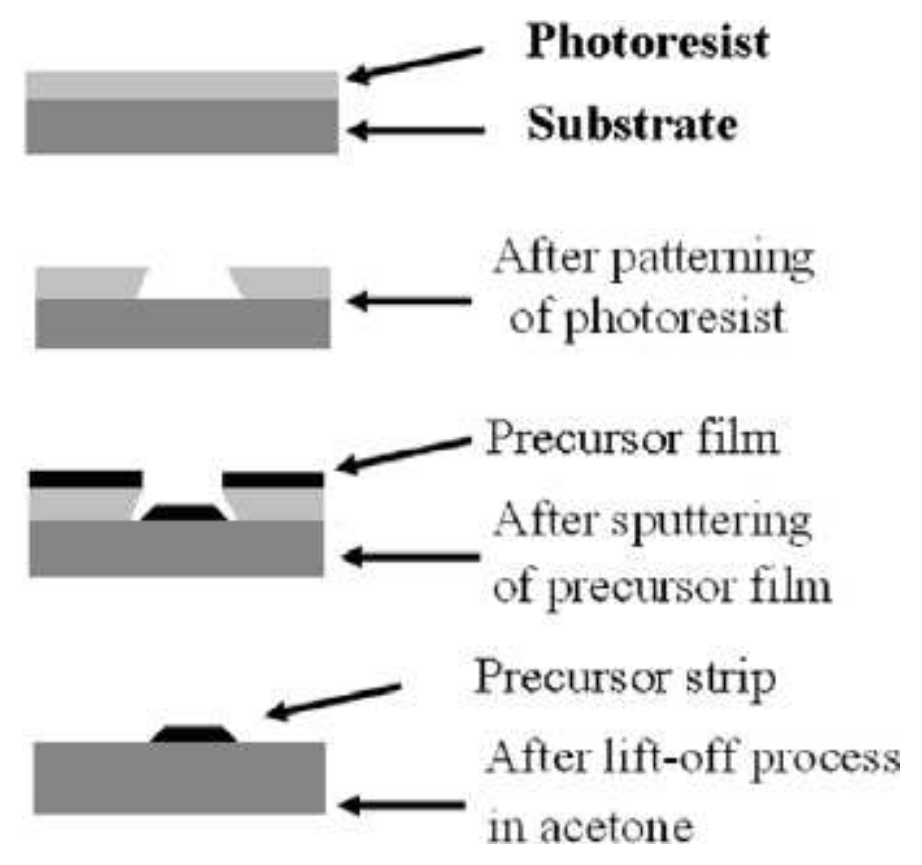

Figure 5. Pattern transfer process using photolithographic liftoff [44].

Figure 6. Cartoon of the Hall Effect (a), a typical van der Pauw geometery used for evaluation of hall voltage (b) [45] 
Figure 7. Powder processing workflow (top) W:ITO target after sintering at $550 \mathrm{C}$ in N2 (bottom, upper), Ni:ITO ready for loading into sputter chamber (bottom, lower) and source powder loaded into die for hydraulic pressing for densification (bottom right). 
Figure 8. MHI Microheater test setup for TCR characterization to $400 \mathrm{C}$ (top) Tube furnace setup for measurement of strain at elevated temperatures (bottom) 
Figure 9. Jig used for room temperature evaluation of compressive gauge factor. Ni:ITO composites are deposited on YSZ substrates and are bonded to a Kapton carrier for handling and electrical connections. 
Figure 10. ITO strain gage fabricated on thin alumina substrates. This gage is bonded to a CMC test article. 
Figure 11. ITO strain gage array processed on HVOF alumina/Aluminum mandrel (top left) Release layer failure during ITO liftoff (top right) Severe cracking of HVOF alumina due to release layer swelling (bottom). 
Figure 12. ITO strain gages on flexible 40 um thick $3 \mathrm{~mol} \%$ YSZ substrates.

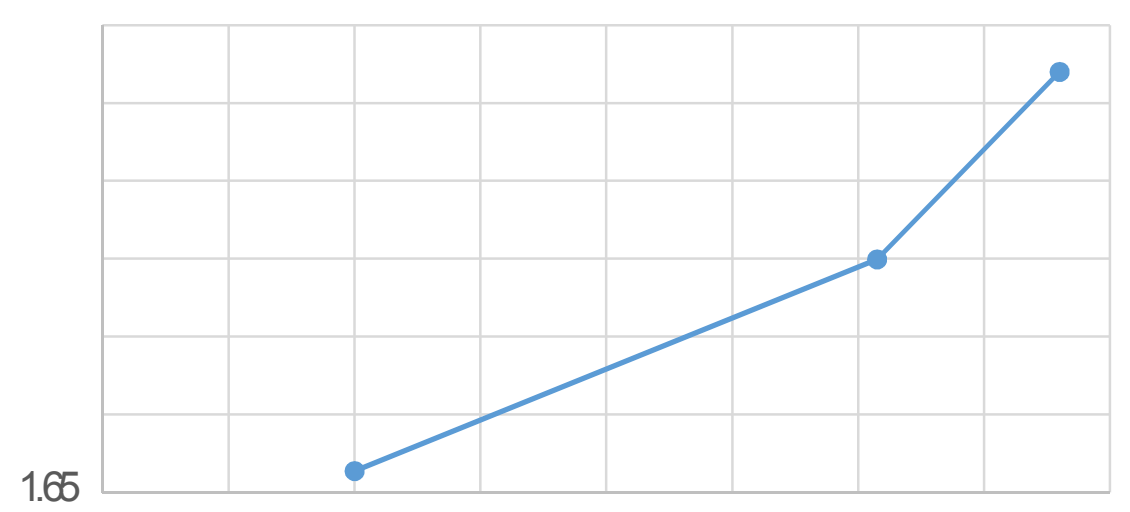

Figure 13. Non-linear strain response of a 95 wt. \% W:ITO composite. 
Figure 14. Casino simulations for electron interaction energy decay @ 20kV and $10 \mathrm{~nm}$ beam diameter for ITO (top) and nickel (bottom) 


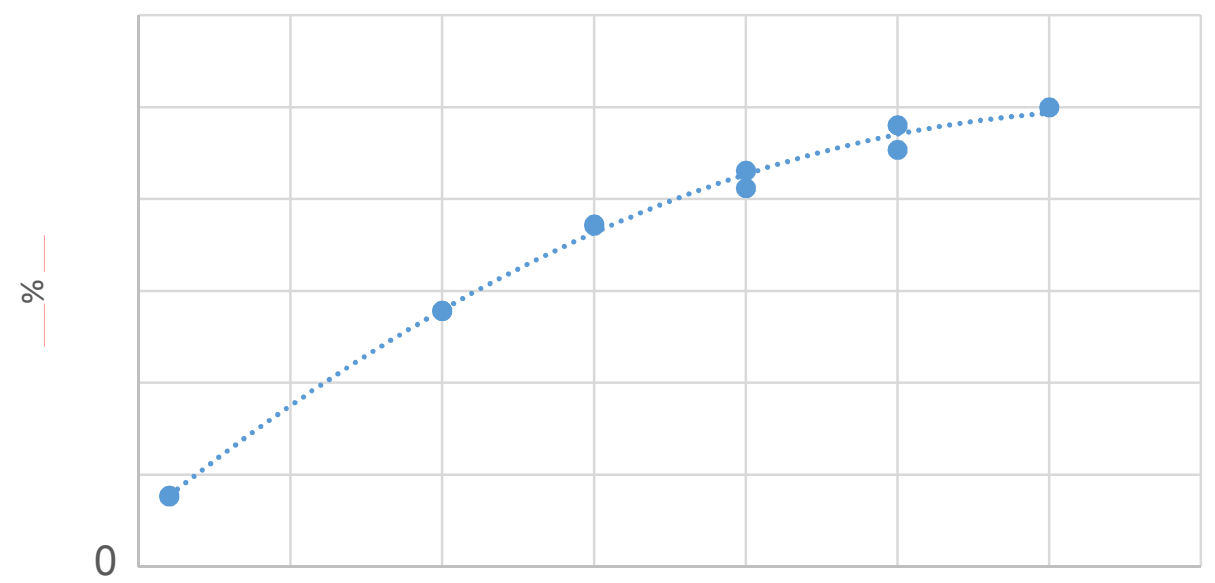

Sample Position

Figure 15. Palladium content as determined by EDS for various Pd:ITO composite samples.

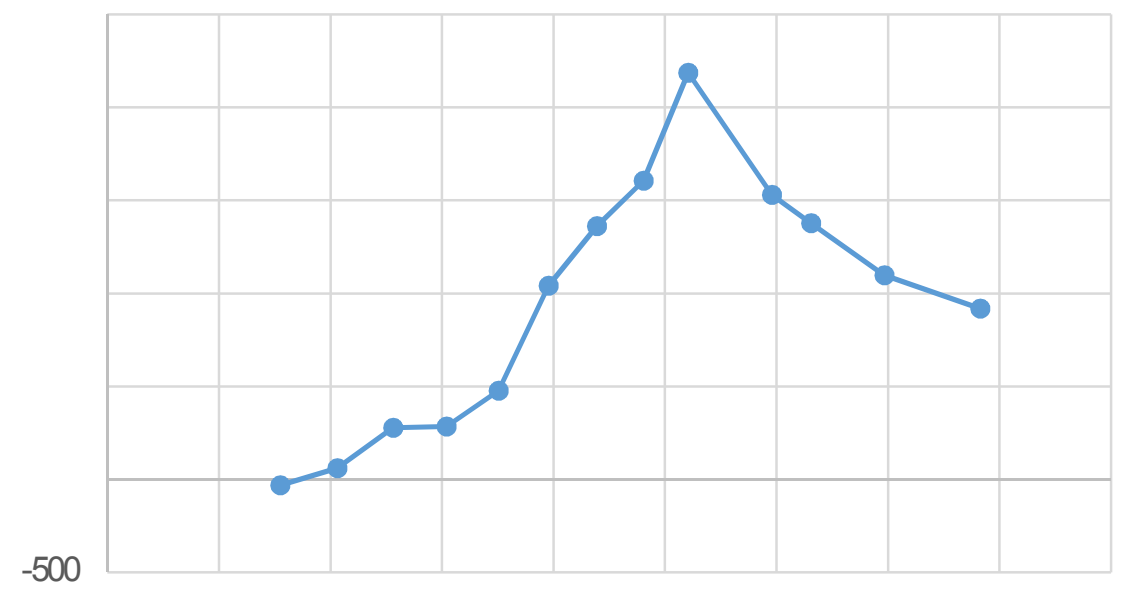

Figure 16. Plot of TCR evaluated at $200 \mathrm{C}$ of various Pd:ITO composites. 


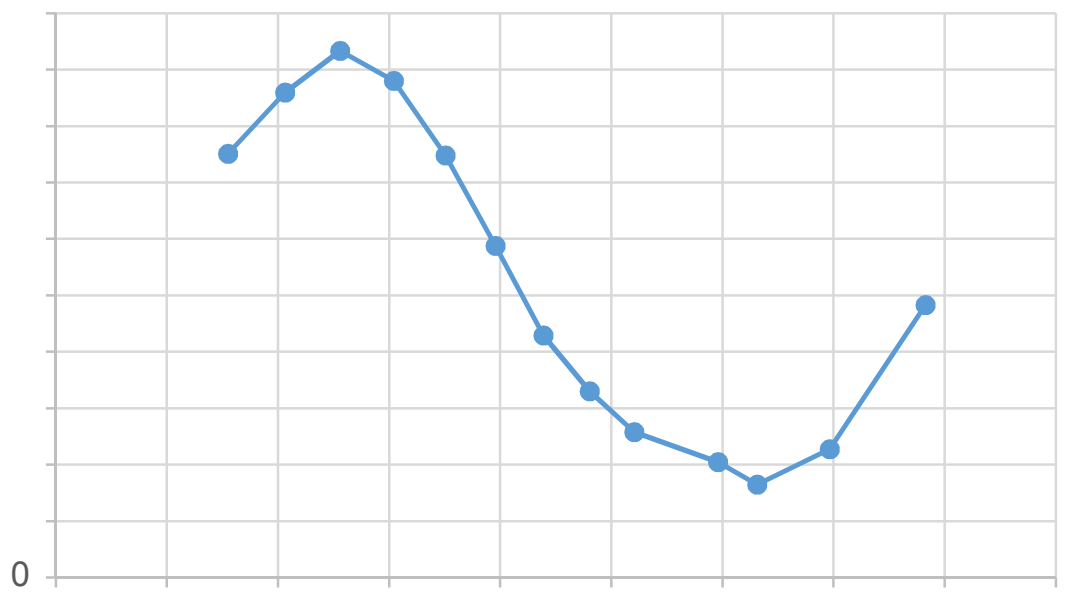

Figure 17. Pd:ITO strain gauge resistance as a function of increasing palladium. 
Figure 18. Pd:ITO SEM image. There is decreasing palladium content and a notable film morphology difference across the shown resistor stripe (top) schematic image of micromasking caused by oblique deposition angles and photoresist thickness (bottom). 


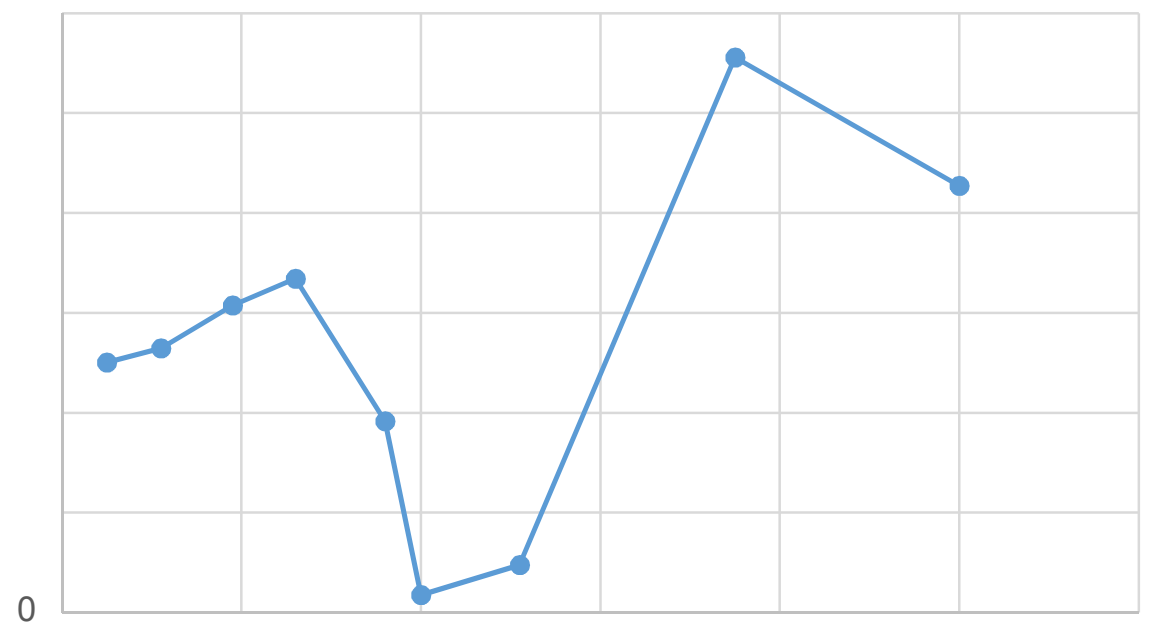

Figure 19. Measured film stress of various Ni:ITO confocally sputtered composite films with a nominal thickness of 0.5 micron measured before annealing. 

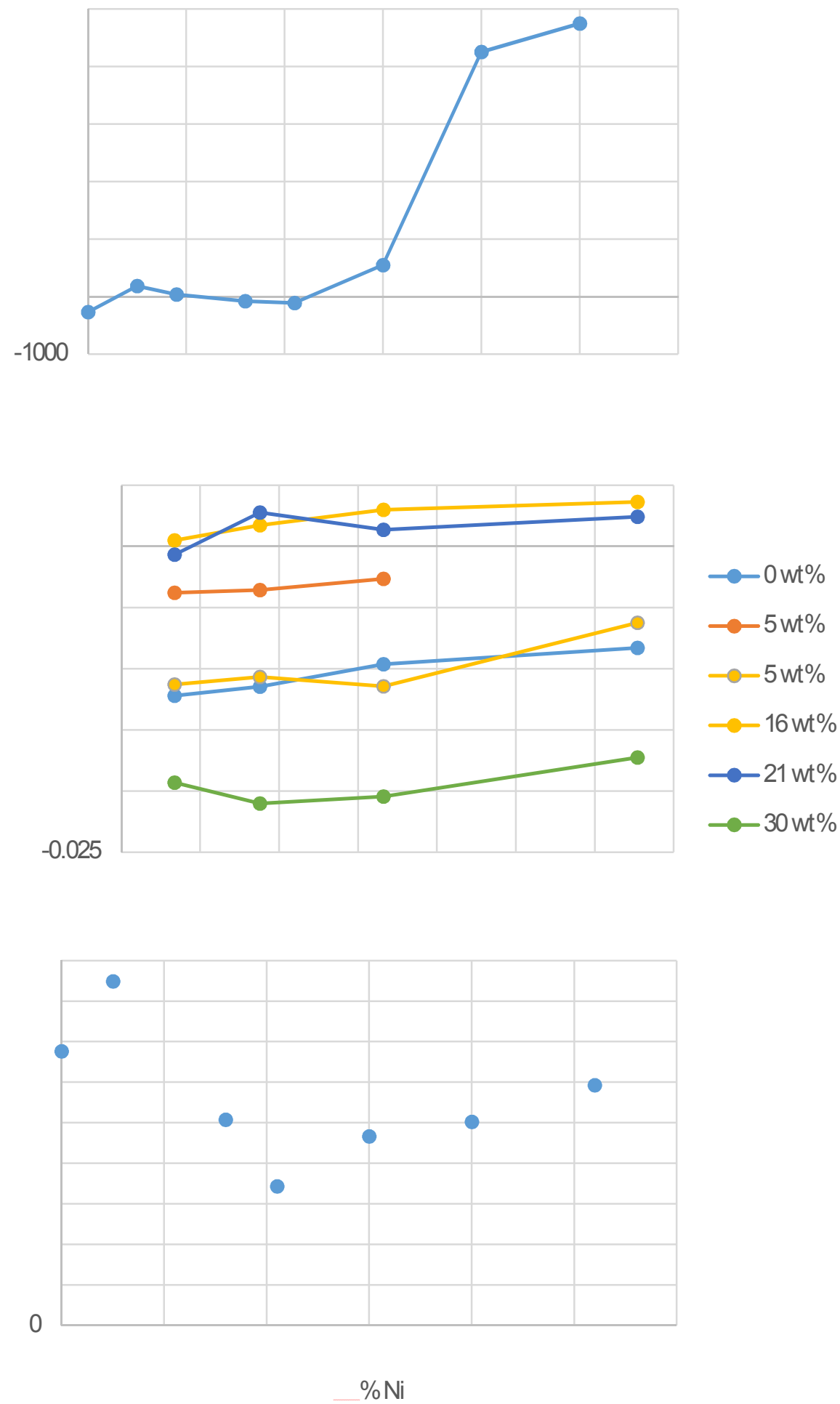

Figure 20. TCR (a), linearity of compressive gage factor (b) and room temperature compressive gage factor of confocally sputtered Ni:ITO composites (c). 
Figure 21. Cross sectional SEM of confocally co-sputtered Ni:ITO composites on silicon substrates. 
Figure 22. Secondary electron SEM images collected from Ni:ITO confocally co-sputtered composites on YSZ substrates. 

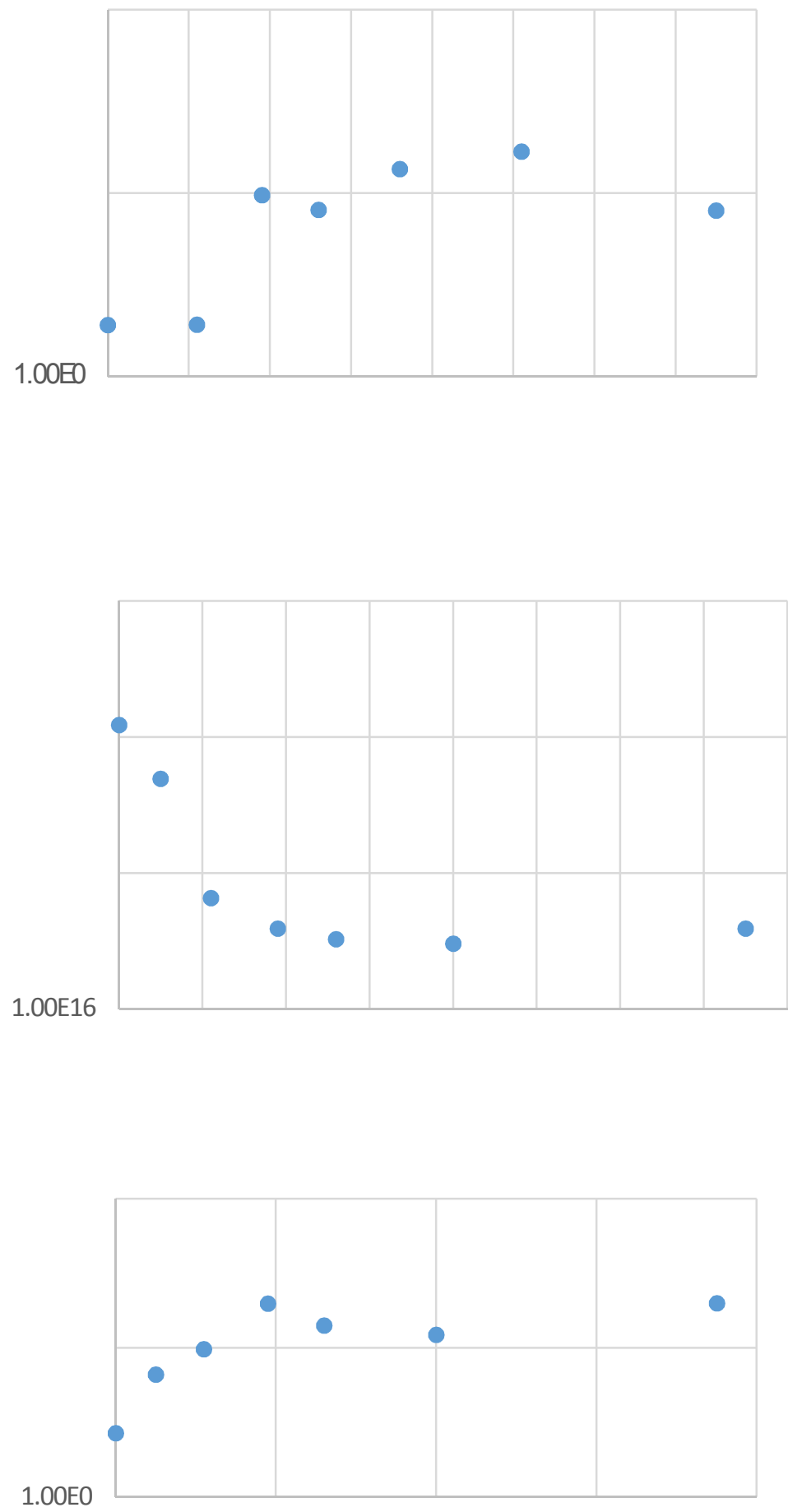

Figure 23. Sheet resistance, carrier concentration and hall mobility of various Ni:ITO films. 